\title{
The Response of Area MT and V1 Neurons to Transparent Motion
}

\author{
Robert J. Snowden, ${ }^{a}$ Stefan Treue, Roger G. Erickson, ${ }^{\mathrm{b}}$ and Richard A. Andersen \\ Department of Brain and Cognitive Sciences, Massachusetts Institute of Tcchnology, Cambridge, Massachusetts 02139
}

An important use of motion information is to segment a complex visual scene into surfaces and objects. Transparent motions present a particularly difficult problem for segmentation because more than one velocity vector occurs at each local region in the image, and current machine vision systems fail in these circumstances. The fact that motion transparency is prevalent in natural scenes, and yet artificial systems display an inability to analyze it, suggests that the primate visual system has developed specialized methods for perceiving transparent motion. Also, the currently prevalent model of physiological mechanisms for motion-direction selectivity employs inhibitory interactions between neurons; such interactions would silence neurons under transparent conditions and render the visual system blind to transparent motion. To examine how the primate visual system solves this transparency problem, we recorded the activity of direction-selective cells in the first (area V1) and in a later (area MT) stage in the cortical motion-processing pathway in behaving monkeys. The visual stimuli consisted of random dot patterns forming single moving surfaces, transparent surfaces, and motion discontinuities. We found that area $V 1$ cells responded to their preferred direction of movement even under transparent conditions, whereas area MT cells were suppressed under the transparent condition. These data suggest a simple solution to the transparency problem at the level of area $\mathrm{V} 1$. More than one motion vector can be represented at a single retinal location by different subpopulations of neurons tuned to different directions of motion; these subpopulations may represent the early stage for segmenting different, transparent surfaces. The results also suggest that facilitatory mechanisms, which unlike inhibitory interactions are largely unaffected by transparent conditions, play an important role in direction selectivity in area $\mathbf{V} 1$. The inhibitory interactions for different motion directions for area MT neurons may contribute to a mechanism for smoothing or averaging the velocity field, computations thought to be necessary for reducing noise and interpolating moving surfaces from sparse information.

\footnotetext{
Received Nov. 26, 1990; revised Mar. 21, 1991; accepted Apr. 11, 1991.

This work was supported by NIH Grant EY07492. R.J.S. was supported by a postdoctoral fellowship from Whitaker College, MIT, and R.G.E., by NIH Postdoctoral Fellowship EY06043. We wish to thank Gail Robertson, Joseph Goddard, Richard Keough, and Stephen Marchetti for technical assistance and Catherine Cooper for editorial assistance. We also wish to thank Noberto Grzywacz for critically reading an earlier draft of the manuscript.

Correspondence should be addressed to Richard Andersen, E25-236, Department of Brain and Cognitive Sciences, M.I.T., Cambridge, MA 02139.

a Present address: School of Psychology, University of Wales, Cardiff CF1 3 YG, UK.

${ }^{\mathrm{h}}$ Present address: Section of Neuroanatomy, Yale University School of Medicine, 333 Cedar Street, New Haven, CT 06510.
}

Copyright (C) 1991 Society for Neuroscience $0270-6474 / 91 / 112768-18 \$ 03.00 / 0$
Motion transparency exists whenever two different motions occur at the same local region in an image. It is quite common in natural images, being found under a variety of movement conditions. An obvious example of motion transparency is the view one receives while looking through the window of a moving vehicle in the rain with water streaking down the glass. A less obvious, but perhaps more common, instance of transparency occurs when a shadow moves across a textured background. If only a single motion vector is allowed at each local region in the image, then one would perceive either the shadow border dragging the texture along with it, or the shadow border being rendered stationary by the texture. Specular reflections represent another potential transparent condition during movement. For instance, when a person wearing glasses rotates his head, the specular reflections remain stationary, yet we do not perceive the head moving and the spectacles remaining still. Even motion discontinuities or "borders," which are generated by object motion or observer motion, are a type of motion transparency. In the local region of the motion border, there is the differential motion of the object and the surround.

Computer algorithms developed to analyze moving images have considerable difficulty with motion transparency (Fennema and Thompson, 1979; Horn and Schunk, 1981; Heeger, 1987; Yuille and Grzywacz, 1988; Bülthoff et al., 1989; Wang et al., 1989). Each involves calculating the local motion components and integrating them, to smooth or average the local velocity field. This computation is typically performed to improve signal-to-noise ratios, to interpolate motion across areas of the image where there is sparse data, and to solve the aperture problem. An unfortunate result of this computation is that every point in the image can only have a single motion vector assigned to it, and as a result, these algorithms are blind to motion transparency. For instance, under transparent conditions in which there is motion of the same speed but in opposite directions, these models would report no motion at all. The fact that artificial systems have such difficulty analyzing transparency, and that its occurrence is so frequent in natural scenes, suggests that the human visual system has developed specialized methods for perceiving it.

Motion transparency also presents difficulties for current models of motion analysis by the primate visual system. The prevalent model for motion-direction selectivity employs inhibitory interactions between groups of neurons (Barlow and Levick, 1965). Such inhibitory interactions would suppress motion-selective cells in transparent situations and render the visual system blind to it, much like the computer systems mentioned above. On the other hand, facilitatory mechanisms for direction selectivity, originally discussed by Barlow and Levick (1965) and observed in several studies (e.g., Ganz and Felder, 1984), would be unaffected by transparent stimuli. At a higher stage than initial measurement of motion direction, the two 
influential models of motion perception of Reichardt (1961) and Adelson and Bergen (1985) both involve subtracting the outputs of oppositely tuned direction detectors, which would give a zero output to opposite, transparent motions.

The ability to sort out the different motion components in transparent moving stimuli extends to the oculomotor system. Kowler and her colleagues (Kowler et al., 1984) have demonstrated that subjects are able to pursuc a moving textured ficld perfectly in the presence of a superimposed stationary field, and vice versa. Also, the ability to see transparent motion presumably extends to nonhuman primates. The rhesus monkey has been shown to have motion-processing capacities similar to humans; in particular, both species can perform similarly in reacting to a three-dimensional rotating hollow cylinder merely through the two-dimensional projection of the cylinder (Siegel and Andersen, 1988). As this involves "transparent motion," it is therefore most likely that these monkeys can also see transparent motion and thus are a suitable animal with which to explore the mechanisms that lead to this percept.

In the primate brain, motion information appears to be processed in a hierarchical manner. Neurons early in the visual system respond well to moving objects but do not show a differential response to movements in different directions. The first location to do so is the striatc cortcx, arca V1 (Hubcl and Wicscl, 1968). In this area, around one-third of the cells have a directional response, and these cells seem to be concentrated in the upper sublayers of layer $4(4 \mathrm{~B}, 4 \mathrm{C} \alpha, 4 \mathrm{~A}$ ) and in layer 6 (Hawken et al., 1988). A strong projection leads from both layer 4B (Maunsell and Van Essen, 1983; Shipp and Zeki, 1985) and layer 6 (Fries et al., 1985) to area MT (or V5), whose neurons are almost exclusively directional (Zeki, 1974; Albright, 1984; Mikami et al., 1986a). Damage to this extrastriate area compromises performance on visual motion tasks, but spares other visual functions, such as contrast sensitivity to stationary gratings (Siegel and Andersen, 1986; Newsome and Paré, 1988). Such a hierarchy of projections suggests that each area may play a different role in motion perception (e.g., Maunsell and Van Essen, 1983; Movshon et al., 1985; Saito et al., 1986; Tanaka et al., 1986; Siegel and Andersen, 1990; Andersen et al., 1990a), with area MT claborating the information provided by V1.

To gain insights into how a biological system processes complex visual environments that contain transparent motions, we have recorded the response of neurons from both areas $\mathrm{V} 1$ and MT in the alert monkey to unidirectional motions, transparent motions, and motion boundaries. We found the cells in area V1 to respond well to their preferred direction of motion even in the transparent condition, whereas area MT neurons were substantially inhibited under the same transparent conditions. These results suggest that the primate visual system solves the transparency problem by allowing, in area V1, more than one motion vector to be represented at each local region in the image. As a result, subpopulations of V1 neurons are tuned to different directions of motion at the same retinal location, perhaps representing the early stage for segmenting different, transparent surfaces. In area MT, the inhibitory interaction of opposed motions may contribute to the smoothing or averaging of the velocity field that is a feature of both the artificial motion analysis systems and models of the primate visual system mentioned above, and is used to reduce noise and interpolate surfaces from moving features. The differential processing of direction information by areas V1 and MT provide further evidence for a hierarchical system of motion analysis.
Preliminary versions of the results presented here have appeared elsewhere (Erickson et al., 1989; Snowden et al., 1990).

\section{Materials and Methods}

Preparation of animals. Two male rhesus monkeys (Macaca mulatta) were used. The animals were trained to fixate in a dimming-detection reaction-time task with the head immobilized. Each trial was initiated with the illumination of a light-emitting diode (LED), which the animal was required to fixate after pulling back upon a lever within $800 \mathrm{msec}$. After a randomized period of between 3 and $4 \mathrm{sec}$, the LED dimmed, and if the animal released the lever within $150-600 \mathrm{msec}$ after the dimming, he received a drop of apple juice reward; the next trial took place after an interval of approximately $5 \mathrm{sec}$. The animal's eye positions were monitored during the fixation period by the magnetic search coil technique (Robinson, 1963; Judge et al., 1980), and if the animal's eye moved at a speed above 15 degrees/sec, the trial was terminated without reward. Eye position was monitored every $35 \mathrm{msec}$, and the standard deviation of eye position on the successful trials was less than 9 min arc for each of the animals (mean, $6.1 \mathrm{~min}$ arc). Details of the training and surgical procedures have been published previously (Andersen and Mountcastle, 1983; Golomb et al., 1985; Andersen et al., 1990b,c).

Stimuli. The animal sat in a primate chair placed $57 \mathrm{~cm}$ from a monitor. The experimental room was dimly lit (0.01 lux), and screen luminance was also 0.01 lux. The screen was surrounded with black cardboard, which could be used for projecting hand-held stimuli. The stimuli used for quantitative analysis were all random dot patterns undergoing apparent motion (Fig. 1). For informal testing and receptive field mapping, computer-generated and hand-held bars were also used. Random dot patterns were produced by plotting points at random locations within a circle. To produce movement, the coordinates of each point in the next frame were suitably changed. Any point that now fell outside the circle was wrapped to the opposite side. Thus, the effect was of a sheet of random dots moving behind a stationary window. The size of the area, number of dots, speed, and direction of movement were all under experimental control. In addition, each dot was displayed only for a limited lifetime $(500 \mathrm{msec})$ and was randomly repositioned within the pattern upon their disappearance. The dots were given a random starting lifetime so that points died in an asynchronous manner (Morgan and Ward, 1980). In addition, it was possible to make patterns in which the dots were stationary but had limited lifetimes. In the experiments using a "stationary noise" pattern, the stimulus consisted of dots that did not die over the course of the stimulus presentation, while the "dynamic noise" was produced by stationary dots of $48 \mathrm{msec}$ lifetime.

These "movies" were produced in advance of the experiments and stored in the memory of the computer. The stimuli were generated and displayed using two different systems at different times. During our early recordings (which constitutc around $44 \%$ of the V1 cells and $65 \%$ of the MT cells), the stimuli were generated by software running on a PDP $11 / 73$ computer and displayed on a large Hewlett-Packard oscilloscope (P31 phosphor) with a nominal frame rate of $35 \mathrm{~Hz}$ (i.e., each frame was displayed for $28 \mathrm{msec}$ before the next frame was shown). Each stimulus was displayed from stimulus onset to the time of the lever release. The dots were 1700 lux, with a diameter of approximately 1 $\mathrm{mm}$. During later experiments, stimuli were generated via a Number Nine graphics board housed in an AST 386 computer and displayed on a raster display (NEC multisync XL) running at $60 \mathrm{~Hz}$ (each frame therefore lasted $16.6 \mathrm{sec}$ ). Here, the stimulus was divided into three periods: 1 sec stimulus, 1 sec blank, 1 sec stimulus; hence, two stimuli could be presented on each trial, which greatly enhanced the speed of data collection. The dots were similar in luminance and size to the previous setup. No obvious differences have been observed between these different setups.

The stimuli were tailored to some extent to match the properties of the cells being recorded. During the early recordings, we used a smaller field size for area V1 (radius, 1.5 degree; 64 dots per surface $=9.2$ dots/ degree $^{2}$ ) than MT (radius, 3.0 degree; 64 dots per surface $=2.3$ dots/ degree $^{2}$ ) in an attempt to compensate for the smaller receptive fields in V1. However, as we kept the number of dots in the stimulus constant, this in itself means that the dot density is different for these two patterns. In control experiments (see Results), we concluded that dot density (or number of dots in the receptive field) has little effect per se, and so in the later parts of the experiments, we used identical stimuli for both V1 and MT (radius, 1.5 degree; 64 dots per surface $=9.2$ dots $/$ degree $^{2}$ ).

Recording procedure. Recordings were made with glass-coated plat- 


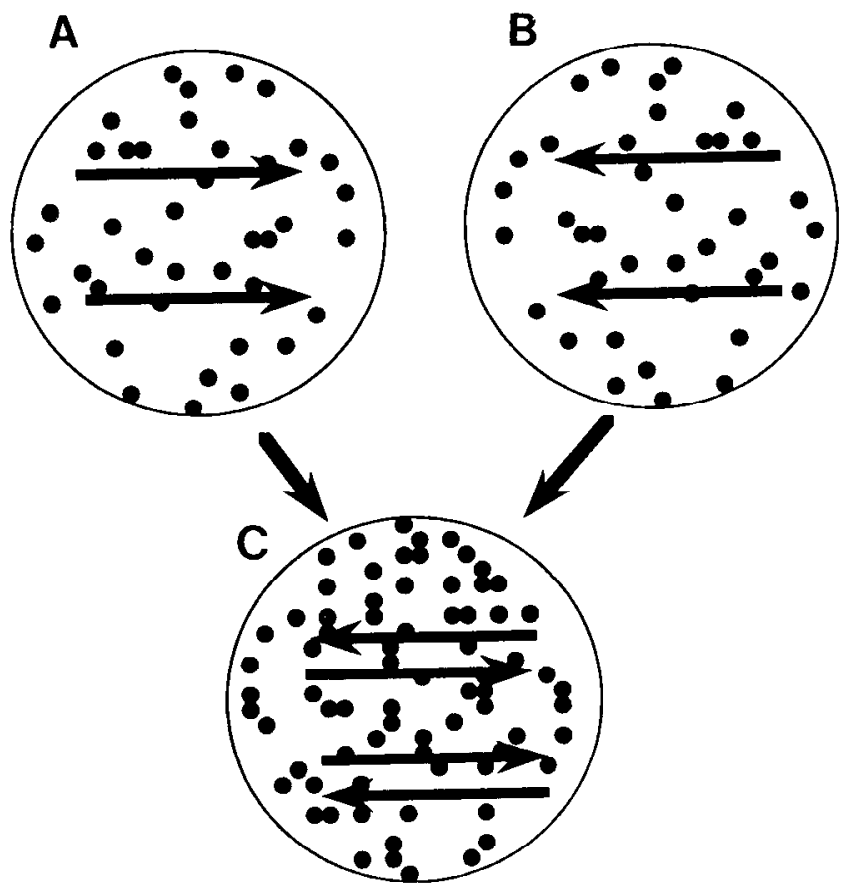

Figure 1. A representation of the stimuli used in this study. Dots were randomly placed within a window and shifted every frame by a set amount. Those falling outside the original window were wrapped to the opposite side of the display. For the single-surface stimuli $(A$ and $B$ ), all dots were displaced by the same amount and in the same direction. The two-surface stimuli (e.g., $C$ ) had two sets of dots that could undergo separate manipulations. In the stimulus portrayed in $C$, the dots moved at the same speed but in opposite directions, and thus this stimulus is equivalent to the superimposition of the stimuli portrayed in $A$ and $B$. In other experiments, the dots could be made to move at any arbitrary angle to one another, to have different densities in each surface, to be stationary or randomly repositioned every other frame, or to be positioned into discrete sections of the pattern.

inum-iridium electrodes advanced through the intact dura. The recording chamber was placed over area V1 such that area MT was accessible with deep penetrations through V1. After each neuron was isolated, an attempt was made to drive the cell by presenting bars and/or dots over various parts of the screen and monitoring activity through an audio feedback, while the animal performed the fixation task. Once the receptive field had been determined, the stimulus was placed in its center. Then, series of blocks of trials were presented until all experiments had been completed or until the cell was lost. A block of trials typically consisted of a set of stimuli whose ability to drive the cell we wished to compare. For example, the first test usually run consisted of a series of five movies that contained eight directions of motion, a stationary pattern, and a blank interval for assessing the spontaneous rate. These five movies were presented in a pseudorandom interleaved order until the monkey had completed 6-10 trials for each movie successfully. The results were then quickly inspected to determine the preferred direction of motion, and the next block of trials was chosen in accord with these results. The tests performed varied depending upon the nature of the cell and the current experimental needs. Typically, up to 10 blocks of trials could be run on a single cell (approximately 600 trials), and this could take around $2 \mathrm{hr}$ to complete. Many cells were lost before all tests could be completed; therefore, the tests were run in a hierarchical fashion depending upon our needs.

Identification of cells and areas. Cells were initially assigned to a visual area based upon their functional properties, receptive field position and size, position relative to other cells, and the depth along a penetration. Over a series of penetrations, the receptive field positions and sizes of the first cells encountered were recorded, and the position of V1 was calculated from the maps published by Dow et al. (1985). Our population of V1 cells was recorded at eccentricities of $0.5-3^{\circ}$ near the vertical meridian. Area MT was identified using physiological criteria including direction selectivity of nearly all cells, receptive field size, and topographic organization (i.e., Gattass and Gross, 1981; Maunsell and Van Essen, 1983; Newsome and Paré, 1988). Our population of MT cells was recorded at eccentricities of $1-10^{\circ}$.

During the last few penetrations in one monkey, we laid down marking lesions at some recording sites by passing DC current through the tip of the electrode. The animal was later killed by an overdose of sodium pentobarbital and perfused transcardially with heparinized saline followed by formalin. Four guide wires were also inserted using the coordinate system of the microdrive shortly after the animal was killed. These were then used as markers for reconstructing where the older electrode penetrations had occurred. The animal's brain was sectioned in the horizontal plane every $40 \mu \mathrm{m}$; every sixth section was stained with thionin for cytoarchitecture, and its neighboring section was stained for myelin by the method of Gallyas (1979). MT and V1 were identified on anatomical grounds, the sites of lesions were identified, and late electrode tracks were reconstructed (Fig. 2). This enabled us to verify the position of MT with respect to our recording sites. The second animal is alive and is currently engaged in other experiments.

Data recording and analysis. Cell discharges were digitized, and their times were recorded by the computer for off-line analysis. The times of all other trial events (e.g., stimulus onset, key down, reaction time, etc.) were also stored by the computer. Poststimulus time histograms were then constructed by collating the data from the same trial types into $50-\mathrm{msec}$ bins and averaging over the number of trials. Examples of such histograms along with the raw spike trains from each trial are shown in Figure 3 along with a representation of the stimulus. For quantitative analysis, a 0.8 -sec interval was chosen (commencing shortly after the response latency), and the mean firing rate and standard deviation within this time period were calculated.

Our total sample of V1 $(N=167)$ and MT $(N=87)$ cells was screened for reliability of response. To be included in our analysis, we had to be able to drive the cell (cells that we could only inhibit were excluded), and we had to be able to get reliable differences between two conditions (e.g., direction of motion). To assess this reliability, we performed a $t$ test between the two conditions, $A$ and $B$, via the formula

$$
\left(A_{\text {mean }}-B_{\text {mean }}\right) / \sqrt{\left(\left(A_{\mathrm{SD}^{2}} / N_{A}\right)+\left(B_{\mathrm{SD}} 2 / N_{B}\right)\right)},
$$

where SD stands for the standard deviation, and $N_{A}$ and $N_{B}$, the number of trials, respectively. Usually, we did not perform this test between every two conditions; rather, we chose the response in preferred, antipreferred, and spontaneous rate conditions and did the comparisons between these. Any cell that had a score $>5.0$ on any test was judged to be significantly affected by our stimuli and was included in the rest of the analysis (V1, $N=130 ; \mathrm{MT}, N=72$ ).

\section{Results}

Response to transparent motion

Individual cells

Initially, the direction and speed tuning of each cell was tested by hand-held stimuli and by quantitative tests involving interleaved trials in which motions in four or eight different directions were presented. The preferred direction of motion was the direction that elicited the greatest mean firing rate, and the antipreferred direction was $180^{\circ}$ from the preferred direction. The responses to single surfaces moving in the preferred direction, antipreferred direction, and a combination of these two stimuli superimposed were then assessed in another block of interleaved trials. The latter stimulus appeared as two transparent sheets of dots drifting through one another, and we therefore termed it the two-surface stimulus. The responses of two representative neurons to these stimuli are shown in Figure 3. The upper part of each section of the figure shows the spike trains elicited on each trial, while the lower part is the poststimulus time histogram averaged over these trials. The left column of this figure depicts the response to the antipreferred direction alone; the middle column, the response to the preferred direction alone; and the right column, the response to the two-surface stimulus. The time of the stimulus presentation is indicated by 


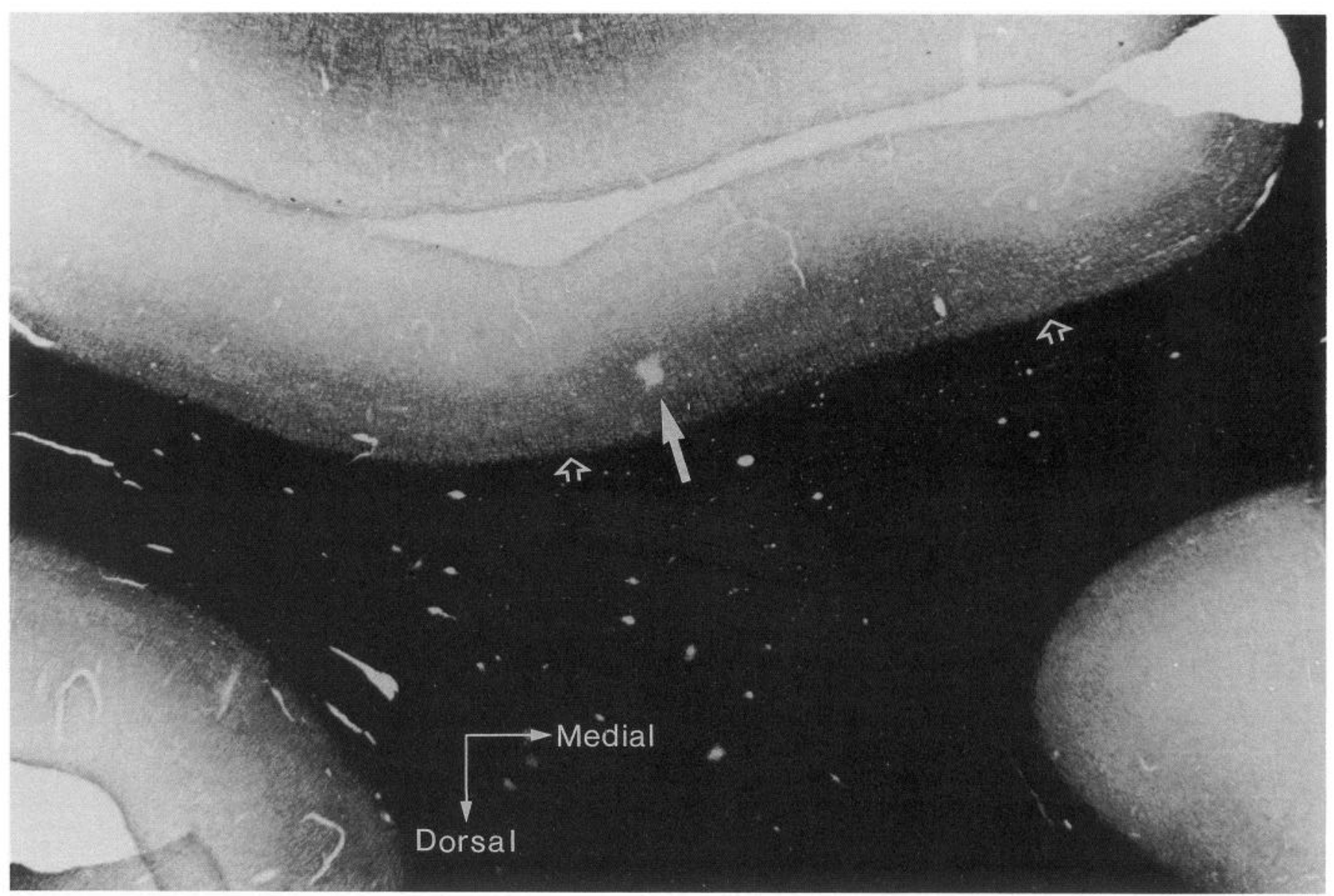

Figure 2. Horizontal section through the superior temporal sulcus. Area MT is visible by its distinctive heavy myelination on the posterior bank of the sulcus (marked by the open arrows in the underlying white manner). A marking lesion is visible in the lateral half of MT (filled arrows).

the bar below each histogram. Inspection of these individual examples shows that these cells have quite different responses to different directions of motions. In order to quantify this difference, we calculated an index of directionality $\left(I_{d}\right)$ between opposite directions of motion:

$$
I_{d}=1-A / P \text {, }
$$

where $P$ is the response to the preferred stimulus and $A$ is the response to the antipreferred stimulus, both after the spontaneous rate (measured by interleaved trials in which the animal simply fixated the LED and no stimulus was presented) was subtracted. An $I_{d}$ of 0.0 indicates no differences between the two directions, while one of 1.0 indicates no response in the antipreferred direction. Values greater than 1.0 indicate that the antipreferred stimulus reduced the level of activity in the neuron to below its spontaneous level. The $I_{d}$ values of the cells in Figure 3 are given in the caption.

The response to the two-surface stimulus is presented in the right column of Figure 3. It is notable that, in the case of the V1 neuron, illustrated in the top half of the figure, the response to the two-surface stimulus was similar to the response to the preferred surface alone. On the other hand, the response of the MT neuron, illustrated in the bottom half of the figure, was considerably less than for the preferred surface. To compare the two-surface and preferred-direction responses quantitatively, we calculated a "suppression index" $\left(I_{S}\right)$ in a manner similar to the one used for the direction index:

$$
I_{\mathrm{S}}=1-\alpha / P,
$$

where $\alpha$ is the response to the two-surface stimulus (again, after the spontaneous rate has been removed). Values less than 0.0 indicate the response was greater to the two-surface than to the preferred stimulus, 0.0 means they were equal, and values greater than 0.0 indicate that the preferred stimulus gave a greater response than the two-surface stimulus. The $I_{S}$ values of the cells shown in Figure 3 are given in the caption.

\section{Population data}

For each neuron on which we performed this experiment, an $I_{S}$ was calculated, and these are presented in terms of their frequency of occurrence for each of our two populations in Figure 4. The cells from V1 show a strong tendency to have a lower $I_{S}$ than those from MT. The median $I_{S}$ for V1 is 0.04 (indicating the response to the two-surface stimulus was similar to the response to the preferred stimulus), with cells falling on either side of 0.0 (indicating suppression in some cells and facilitation in others). The median $I_{S}$ for MT was 0.54 , with some cells being inhibited below their spontaneous rate $\left(I_{s}>1.0\right)$ by the two-surface stimulus. No cells from MT had an $I_{s}<0.0$, indicating that all cells were suppressed below the rate for the preferred stimulus alone. The difference between the two populations' data was confirmed by an independent-samples $t$ test $(t$ $=5.7 ; p<0.0001$ ).

The proportion of directionally selective responses $\left(I_{d}>0.7\right)$ 
Figure 3. Examples of the responses of a V1 and an MT neuron to singleand two-surface stimuli. The circles containing arrows depict the type of stimulus shown on those trials, and the dark bars below the response histograms indicate the time the stimulus was displayed. Each major division of the abscissa is $1000 \mathrm{msec}$. The $\mathrm{V} 1$ cell $(A)$ gives a directional response (favoring movement up and to the right) and gives a response to the two-surface stimulus that is similar in magnitude to the preferred stimulus alone. Thus, this cell had an $I_{d}$ of 0.82 and an $I_{s}$ of 0.16 [see formulas (2) and (3)]. The MT cell $(B)$ is also directional $\left(I_{d}=1.03\right)$ but gives a lower response to the two-surface stimulus than it does to the preferred stimulus alone $\left(I_{s}=0.55\right)$.
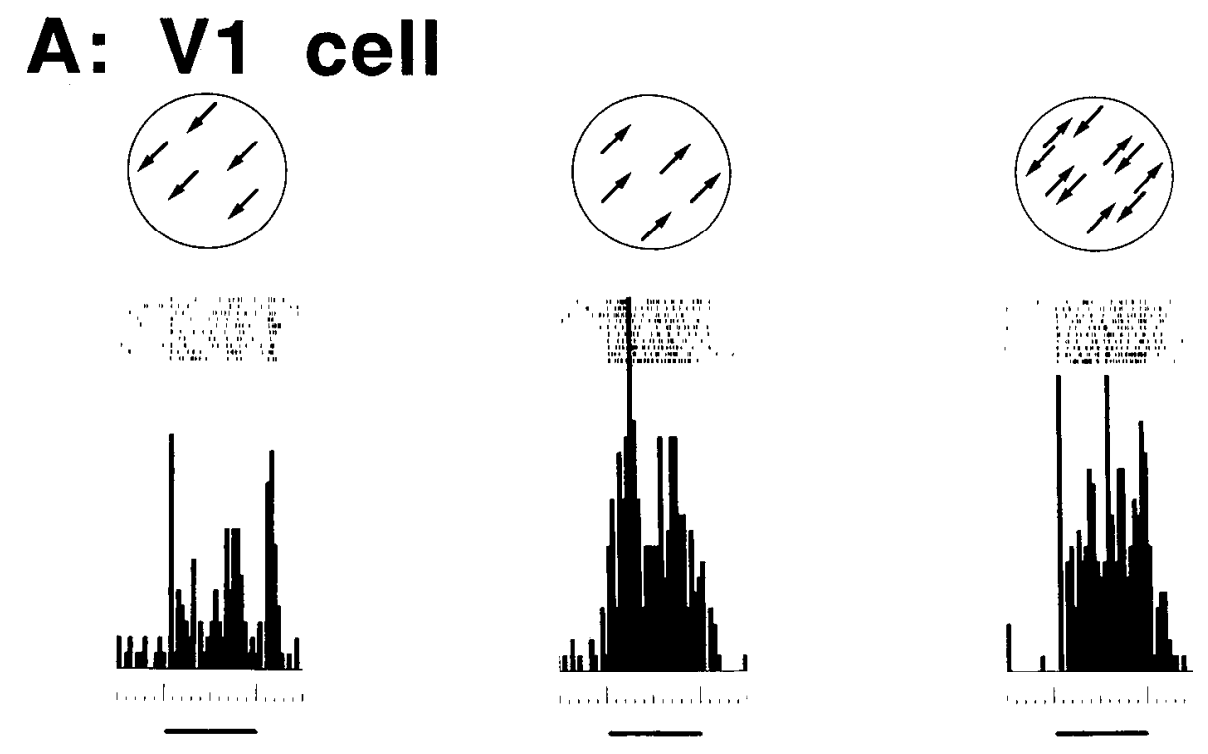

B: MT cell
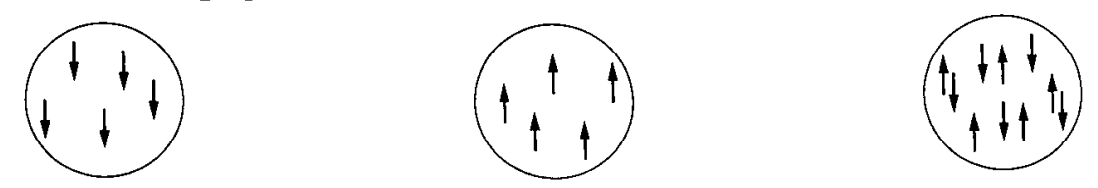
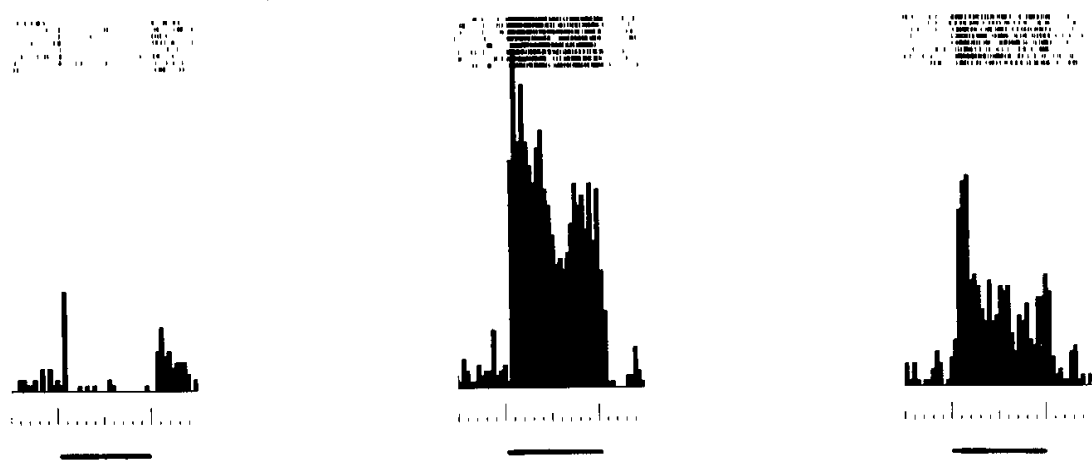

was $30 \%$ in area V1 and $92 \%$ in area MT. This is in agreement with previous estimates (Zeki, 1974; De Valois et al., 1982; Albright, 1984; Mikami et al., 1986a; Hawken et al., 1988). As MT shows both higher $I_{d} \mathrm{~s}$ and higher $I_{s} \mathrm{~s}$ than $\mathrm{V} 1$, it is possible that these indexes may stem from a common cause, that of increased inhibition in the antipreferred direction. Thus, we plotted the $I_{d}$ against the $I_{s}$ in Figure 5 for each neuron from which this information was obtained. The upper section plots the data from area $\mathrm{V} 1$, and the lower section, data from area MT. It can be seen that, in the area of overlap of direction indexes in V1 and MT, which was greatest between about 0.6 and 1.2, V1 still showed considerably lower suppression indexes than area MT. Thus, the difference in suppression indexes between areas V1 and MT cannot be explained solely on the basis of greater directional indices in MT. A comparison of indices was also made within areas. For the V1 cells, we found no significant correlation between these indexes (Spearman rank correlation $=0.14 ; p>0.2)$. For the MT cells, we did find a significant correlation (Spearman rank correlation $=0.45 ; p<$ 0.001 ). This indicates that, within area MT, the $I_{s}$ was related to the $I_{d}$ in a manner such that the greater the $I_{d}$, the greater the $I_{s}$. However, it is also noticeable that many cells that were not inhibited below their spontaneous rate by the antipreferred direction alone still had $I_{s}>0.0$, indicating that this stimulus has an excitatory response when presented alone, but an inhibitory effect when presented in conjunction with the preferred direction. This presumably reflects an inhibition by the antipreferred motion that is masked by an excitatory but unspecific response to high-contrast random dot patterns (also see our discussion of divisionlike inhibition below).

\section{Possible role of dot density}

We were concerned that our rcsults might be influenced by the fact that our two-surface stimuli normally contained twice as 

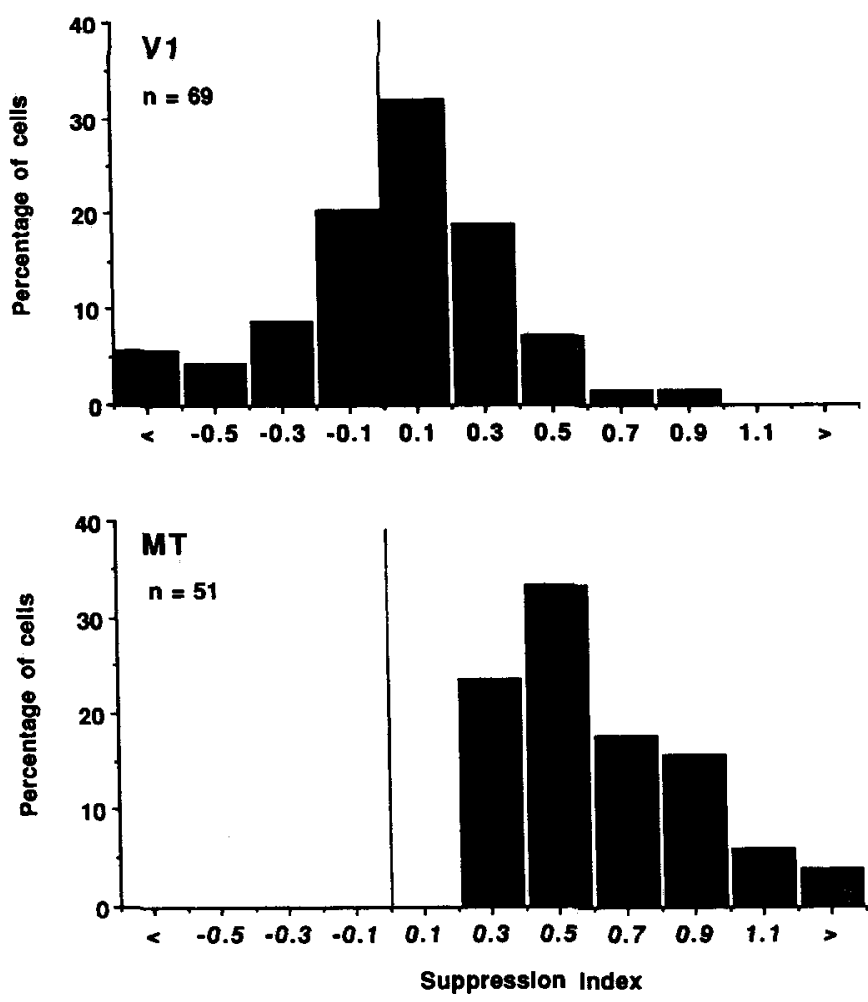

Figure 4. For each of our cells on which the suppression test was performed, we calculated the $I_{s}$, and the frequency of occurrence of this index is plotted for our population of V1 cells (top) and MT cells (bottom). An $I_{s}$ of 0.0 (indicated by the vertical line) means that the cell responded in a similar fashion to the preferred stimulus alone and to the twosurface stimulus. Points to the left of this line indicate a greater response to the two-surface stimulus, while points to the right indicate a smaller response to the two-surface stimulus. The median index for V1 was 0.04 , and for MT, 0.54 . The distribution of the $I_{s}$ in our population of $\mathrm{V} 1$ and MT cells is significantly different $(p<0.0001)$.

many dots as the single-surface stimuli (as a result of superimposing two single-surface stimuli to form a two-surface stimulus). If wc assume that increasing the dot density would increase the response, then we might underestimate the suppression effect. We thus performed a control experiment on cells in both V1 and MT in which we determined the suppression index for a two-surface stimulus made up from two surfaces of either 32 or 64 points. In both cases, the response of the cell to the preferred direction alone was determined with a single-surface stimulus containing 64 points. The data from V1 and MT is portrayed in separate plots in Figure 6. As can be seen from this figure, lowering the density of the two-surface stimulus to equal the density of the single-surface stimulus had no systematic effect on the $I_{s}$. The most likely reason for this result is the rapid saturation of the cells' response with increasing dot density (see Fig. 12). For single-surface stimuli, the saturation usually occurs with just a few dots.

In comparing data from MT and Vl, it should be noted that the receptive field sizes at any given eccentricity are very different, with area MT having larger receptive fields (Gattass and Gross, 1981). Because we used stimuli of the same dot density in area V1 and MT, the number of dots in the receptive fields of the two areas was quite different. To make sure that this would not systematically affect our $I_{s}$ measurements, we obtained responses from eight cells in MT and 12 cells in V1 to
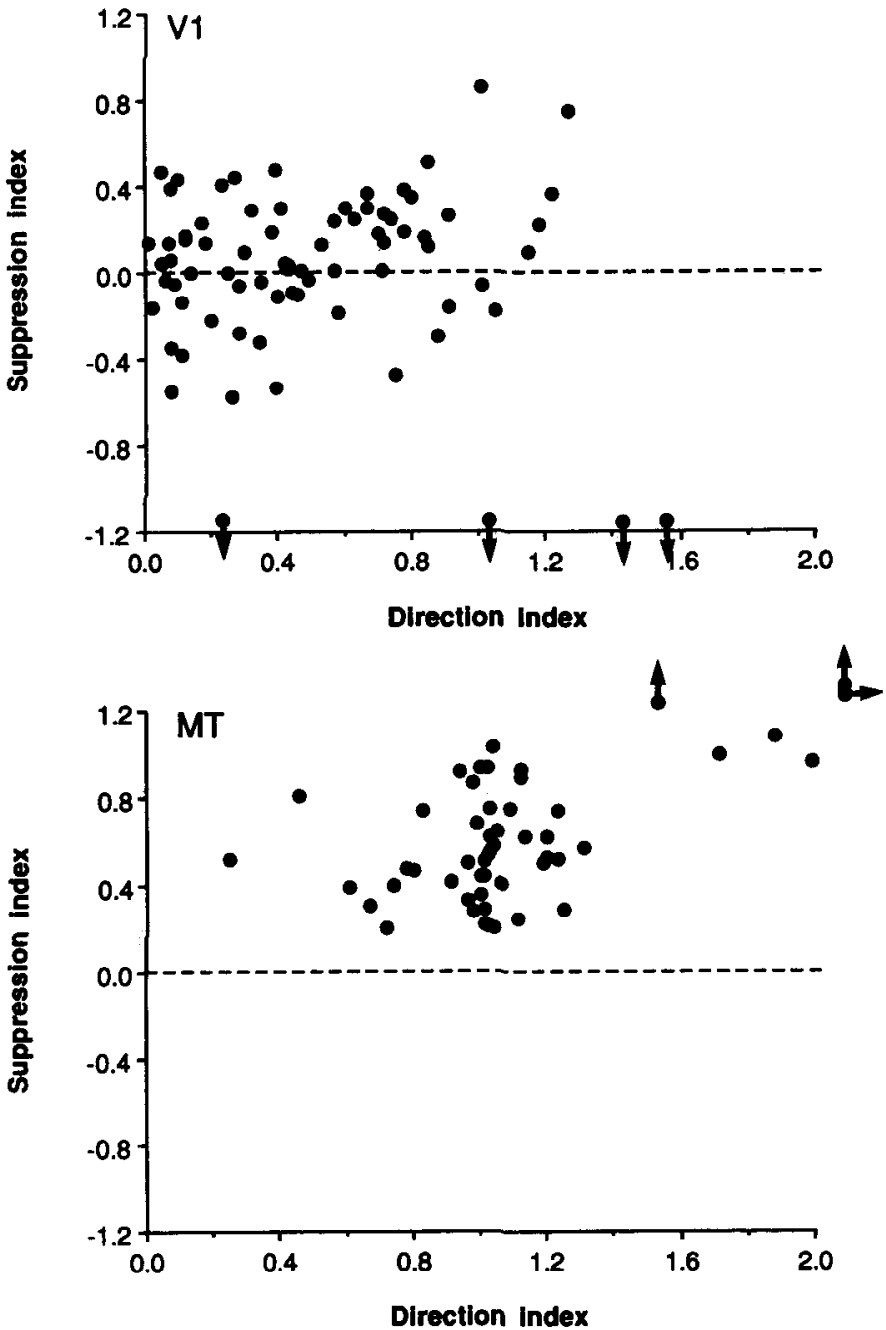

Figure 5. A scatter plot of the $I_{d}$ against the $I_{s}$ for the V1 cells (top) and MT cells (bottom). Points that fell off the scale are indicated by arrows. A statistical test for correlations (Spearman's rank) was performed between the two indexes. The V1 data show no significant correlation between the two indexes $(p>0.5)$, whereas the MT cells do ( $p$ $<0.005$ ), which indicates that cells with a large $I_{d}$ also tend to have a large $I_{s}$

dot densities ranging from 0.45 to $28.8 \mathrm{dots} / \mathrm{degree}^{2}$ in each surface-a 64-fold change in density. Again, no systematic change was found in either area, though it became noticeable that the data obtained from V1 cells at the low densities became erratic, and that the correlation with the values obtained at a higher dot density was poorer. This result is perhaps not surprising, because at the lowest dot density for the $\mathrm{V} 1$ cells, there could exist intervals during which no dots were actually in the receptive field. These controls show that, as long as at least modest dot densities are used, this parameter does not have a substantial effect on the data.

Thus, the addition of the antipreferred direction of movement to the preferred direction of movement causes a suppression of response in many cells. This suppression is apparent in all MT cells and is far stronger than that found in V1.

\section{Effects of stationary and dynamic noise}

The above results show that movement in the antipreferred direction can suppress activity driven by the preferred direction. 

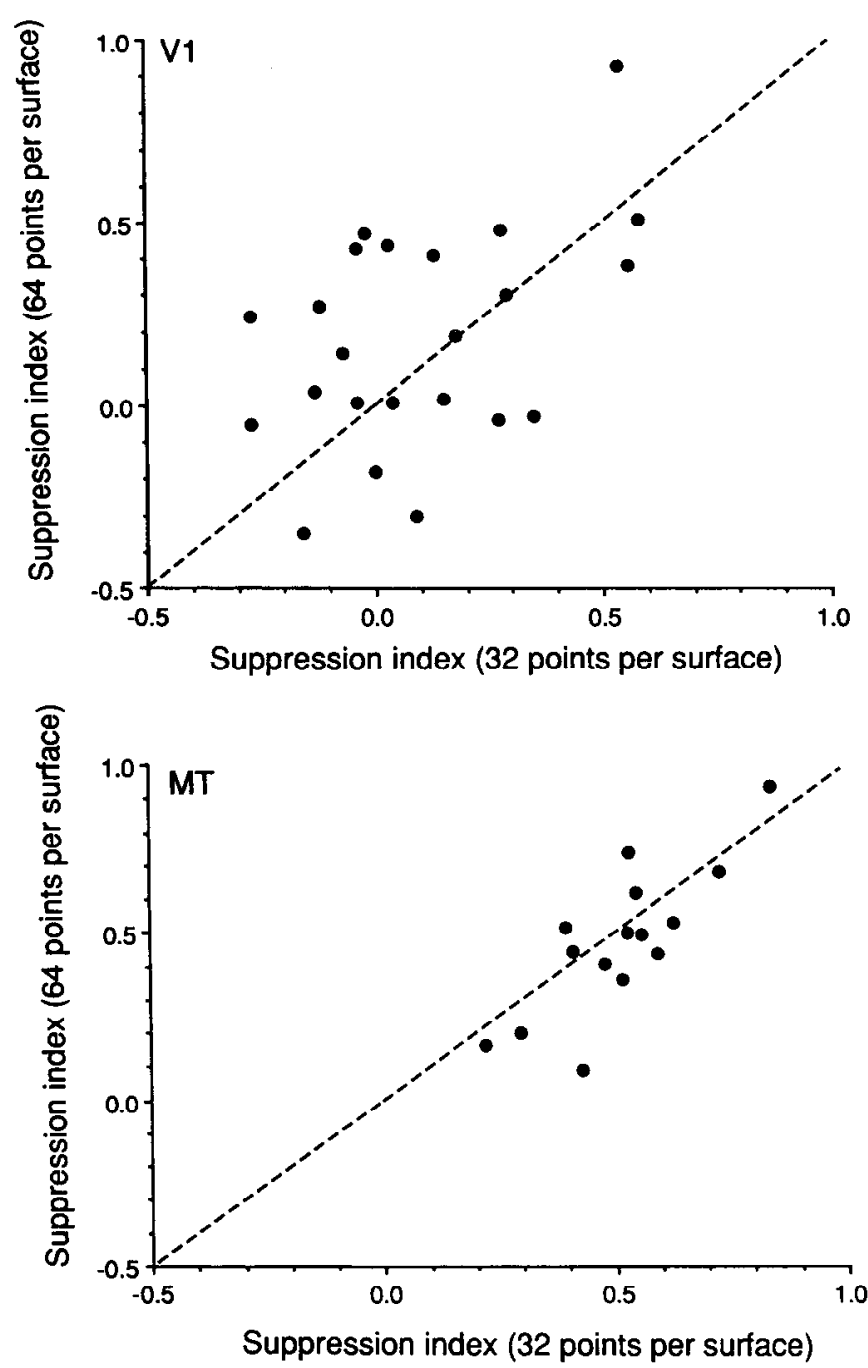

Figure 6. The $I_{s}$ calculated when the surfaces in the transparent condition contained 64 points each is plotted against the same index when the surfaces contained 32 points each. The single-surface stimulus used to determine the response to the preferred direction alone contained 64 points in both cases. The upper section shows the results from V1 cells, and the lower section, MT cells. Both plots show a strong correlation between the two indices, and points fall with approximately equal preference above and below the broken line at $45^{\circ}$, which indicatcs no systematic shift in the $I_{s}$ with dot density. The V1 data have a greater scatter than do the MT data, and this scatter was found to increase with decreasing dot density. This scatter may refiect the statistical probabilities of the number of dots in the receptive fields of the V1 neurons.

However, it is possible that the suppression might have nothing to do with movement per se, but is a more general effect.

We tested this prediction on 13 MT cells by replacing the antipreferred direction with either a stationary pattern or a dynamic noise pattern (see Materials and Methods) in the twosurface stimulus. The response to each stimulus was scaled relative to the response to the preferred stimulus alone, and the mean and SE are shown in Figure 7. Once again, the antipreferred direction caused a large suppression. Both the stationary pattern and dynamic noise also caused some suppression (of similar magnitude), but this was mild compared to the antipreferred movement. These differences were confirmed by nonparametric statistics (Mann-Whitney $U$ test: antipreferred and stationary pattern, $p<0.005$; antipreferred and dynamic noise,

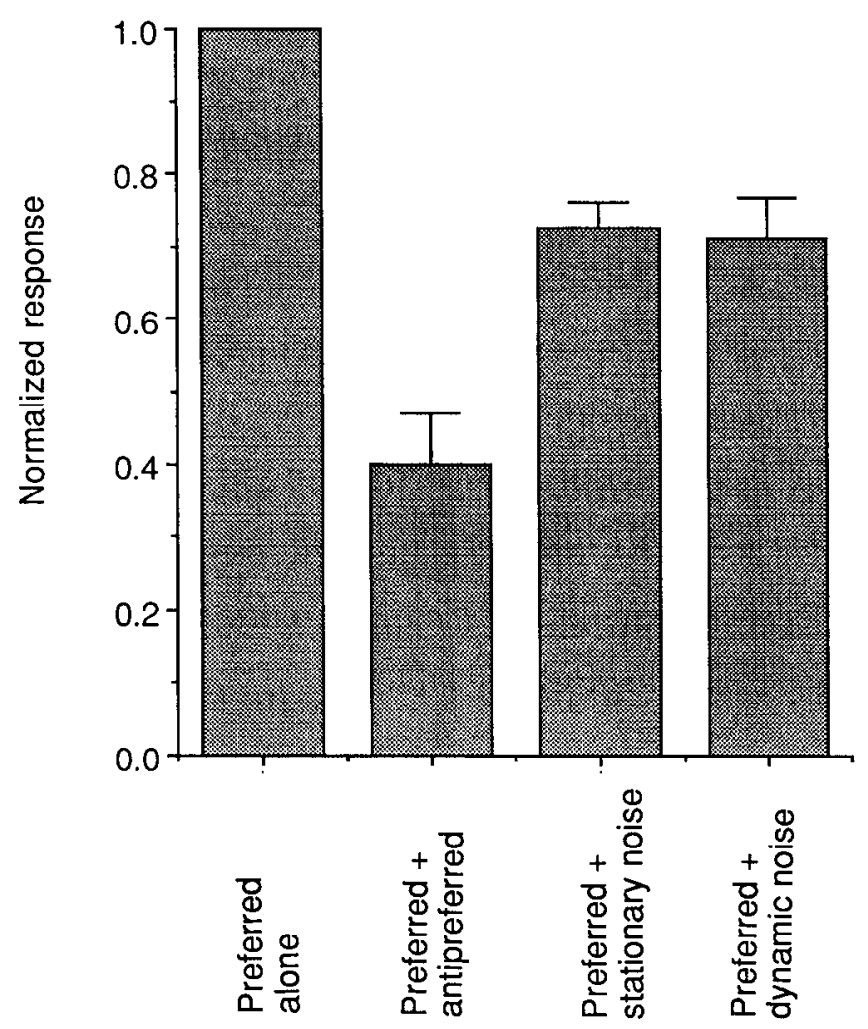

Figure 7. A comparison of the effects on the response of MT cells $(N$ $=13$ ) of adding the antipreferred direction of movement, stationary noise, and dynamic noise to their preferred direction of movement. All stimuli were presented in a pseudorandom order. The response elicited in condition was scaled to the response of the preferred stimulus alone (the preferred stimulus alone therefore has a score of 1.0 ). The mean index is plotted in the form of a histogram, and the error bars indicate one SE. A statistical analysis (Wilcoxon signed-rank) has shown significant differences between the preferred direction alone and all three other conditions and between the antipreferred condition and the stationary and dynamic noise conditions, but no significant differences between the stationary and dynamic noise conditions.

$p<0.01$; stationary and dynamic noise, $p>0.5$ ). These results show that addition of a stationary pattern or dynamic noise do reduce the response compared to the preferred direction alone, but that this suppression is considerably smaller than that produced by the coherent, antipreferred movement.

\section{Motion borders}

The two-surface stimulus contains dots moving in opposite directions. These motion vectors are randomly positioned to produce the impression of two overlapping transparent surfaces. It is of interest to determine whether splitting the different motion vectors into discrete groups, so that the motion is no longer "transparent," but rather appears as a set of motion borders, would also produce the same suppressive effect described above.

An example of this test is shown in Figure 8 for an MT cell. The top two sections of this figure show the response to the antipreferred and preferred direction, respectively. Note that the dots were confined to three stripes within the circle, and that the stripes without dots for the leftward motion are the ones with stripes for rightward motion (the cell was also tested with the alternate arrangement of motion direction and gave very similar results). This cell was direction selective and showed no 

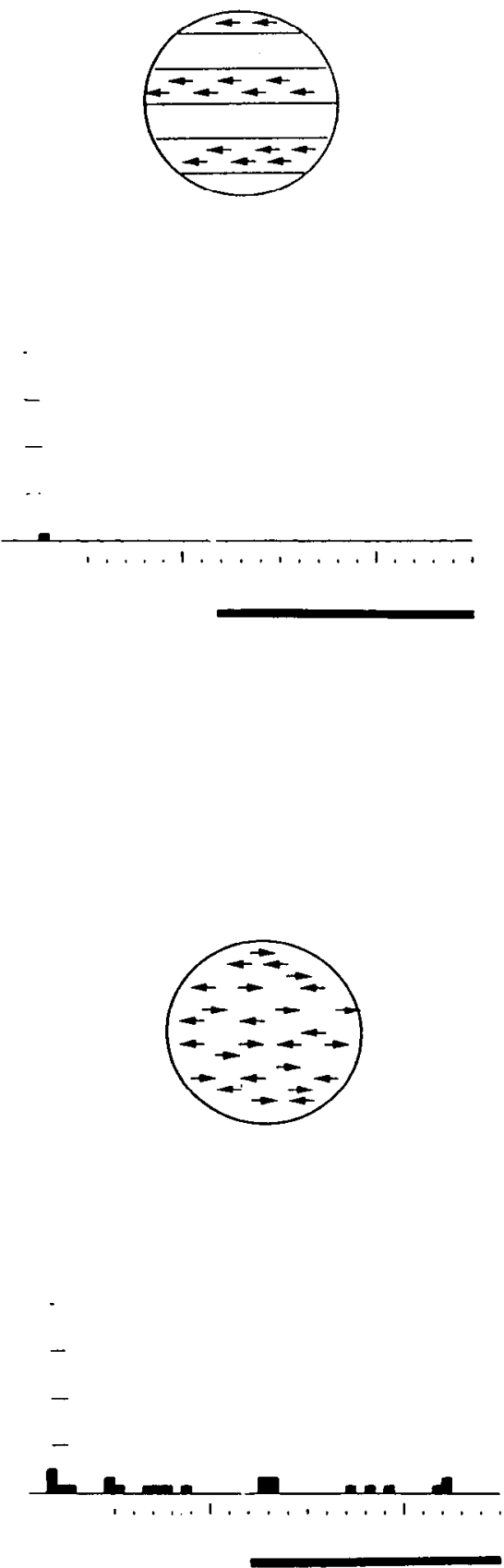

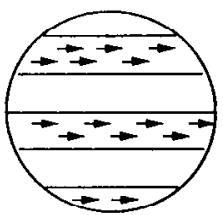

ming
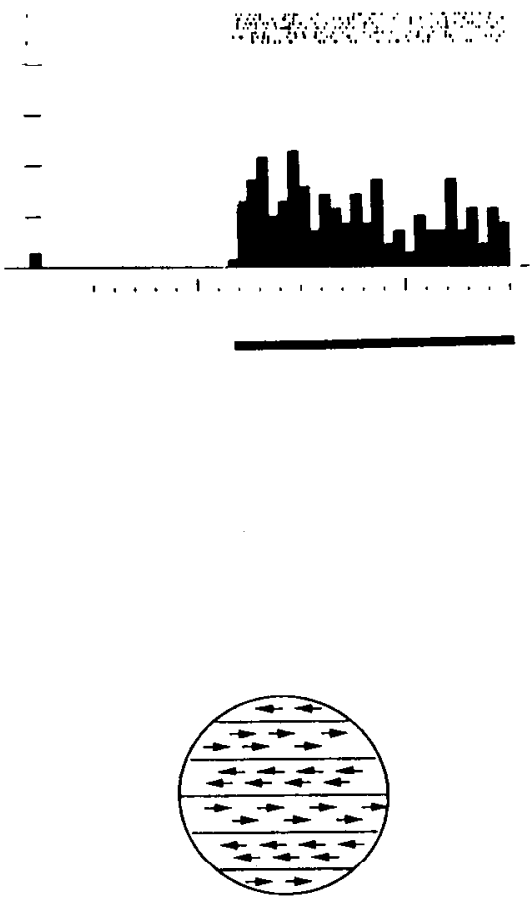

$-$

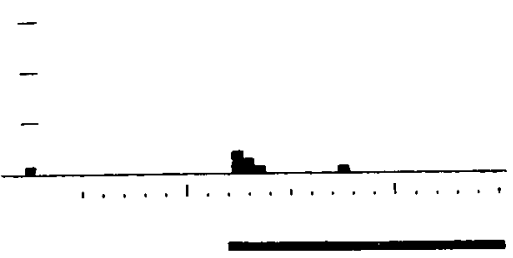

Figure 8. An example of the responses of an MT cell to motion kept in discrete stripes. In the upper sections, only a single direction of motion is present in a stimulus, though the dots are contained within three discrete stripes. Data were also collected when the stripes that are blank in this diagram were the ones filled with dots, and this data was identical in form to that portrayed here. The lower sections show the response of the cell when two motions were within the receptive field (all conditions were pseudorandomly interleaved). Both when the motion vectors were overlapping and when they were in discrete sections, we found a strong suppressive effect. response to its antipreferred stimulus. The bottom right section of this figure shows the response to the superimposition of the two stimuli (now alternate stripes were filled with dots moving in opposite directions). The cell gave little or no response to this stimulus, which was similar to its response to the transparent stimulus, shown at the lower left. Clearly, then, separating the dots into discrete stripes does not allow the cell to respond as it does to the preferred direction alone. We performed a comparison between overlapping (transparent) and segregated (striped) displays by calculating an $I_{s}$ (as above) for each of these displays on $17 \mathrm{MT}$ neurons. Figure $9 \mathrm{~A}$ plots these indexes against one another. As can be seen in this figure, many of the points fall close to a line with a slope of 1.0 , indicating little difference between the results obtained for the separated and transparent stimuli. However, there is a trend for the response to be greater to the separated stimulus (more points fall below than above the broken line at $45^{\circ}$ ), indicating that there was less suppression than under the transparent conditions. We attempted to push this test further in 12 cells by presenting only two stripes (i.e., the upper half moving in one direction and the lower half in the opposite direction and vice versa). We often found that these two stimuli gave very different results (i.e., when the preferred direction was, e.g., in the upper half, the cell responded strongly, while when the preferred direction was in the lower half, the cell gave a very poor response). We therefore averaged the response from the two conditions to compare with the transparent motion stimuli. The data are presented in Figure $9 B$. The result is similar to that obtained with six stripes: the cells are still inhibited below the response to the preferred direction alone, but the suppression is not as strong as under the transparent conditions. Britten and Newsome (1990) have recently reported results very similar to these. 
A
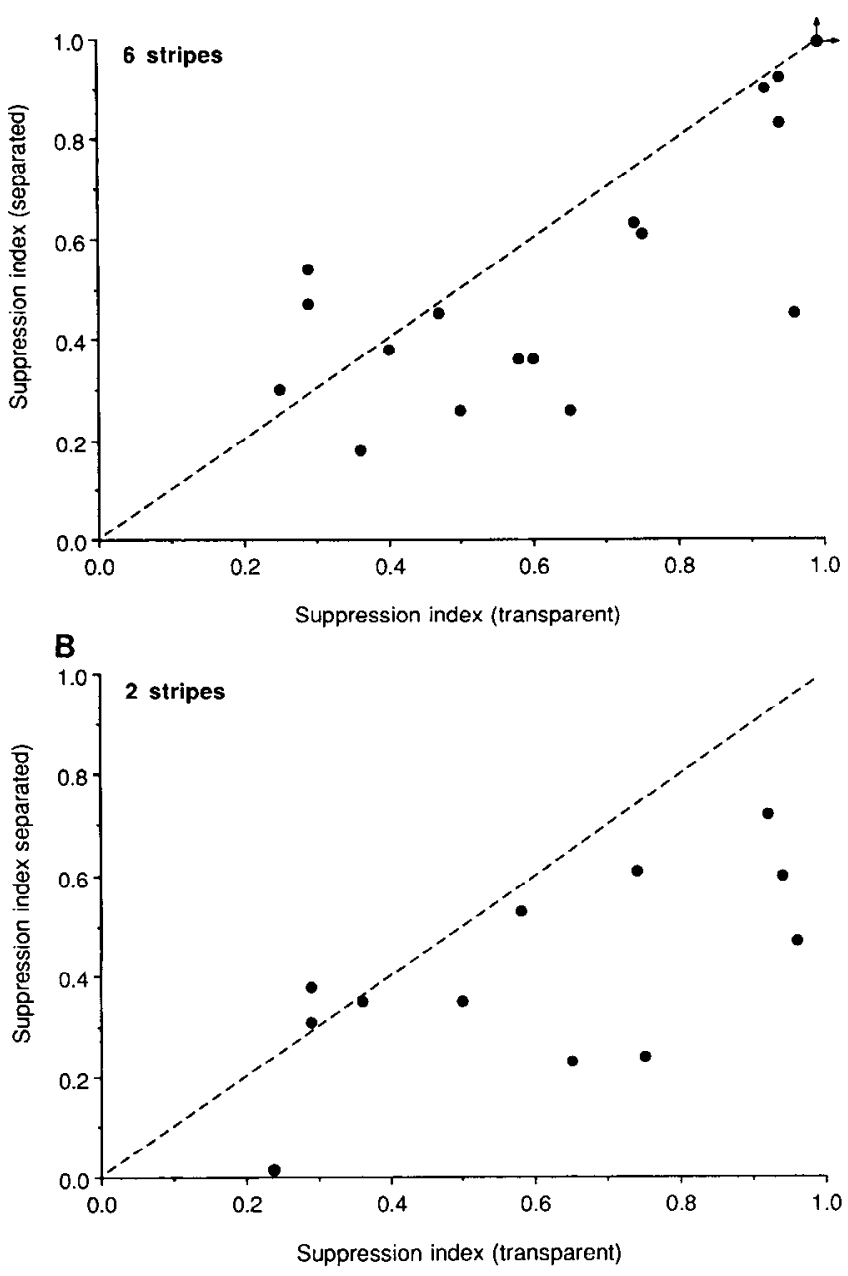

Figure 9. The $I_{s}$ calculated when the motions were superimposed (transparent) and when the motions were in discrete stripes (separated) are plotted against one another for MT cells. If the indexes are exactly the same, points should lie along the broken line at $45^{\circ}$. If the suppression effect were to disappear under the separated condition, the points should lie along the abscissa. $A$, Here, the dots were separated into six stripes (three moving in each direction). Clearly, the points lie much closer to the $45^{\circ}$ line, indicating a strong suppression effect even under the discrete condition. There is, however, a small trend toward having a smaller $I_{s}$ under the discrete condition. The arrows point to two cells that fell off the scale of this graph. $B$, Here, the dots are separated into two stripes (one moving in each direction). The results are similar to those of $A$.

\section{Direction tuning of suppressive effects}

We were interested in the relative degree of suppression generated by directions of motion other than opposite to the preferred direction. Sixty-four dots were always drifted in the cell's preferred direction, and another 64 dots were drifted in one of eight directions, each separated by $45 \mathrm{deg}$. The results of a representative MT cell are shown in Figure $10 \mathrm{~A}$. As can be noted in this figure, directions other than those $180^{\circ}$ from preferred also produced inhibitory effects in that the response to the twosurface stimulus is less than that to the preferred stimulus alone. Figure $10 B$ demonstrates the direction-tuning curve of this neuron for single directions of movement. It is noticeable that the cell is strongly excited by movements $45^{\circ}$ from the preferred direction, yet this same movement $\left(45^{\circ}\right.$ from preferred) causes
A: Tuning of suppression

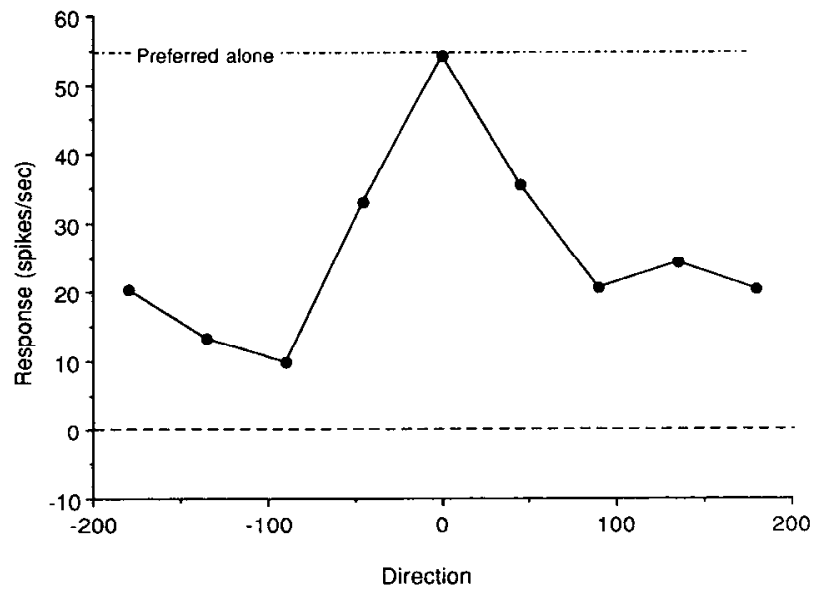

B: Direction tuning

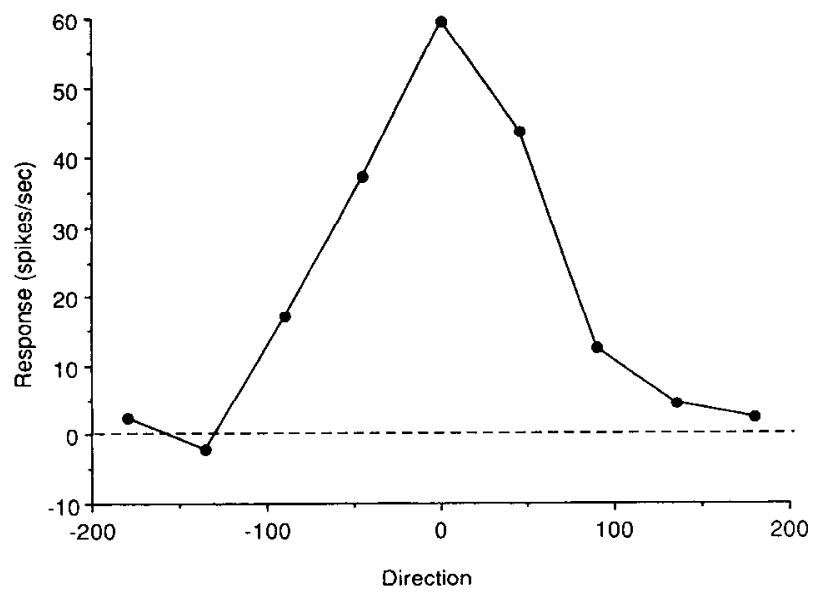

Figure 10. A, The directional tuning of the suppression effect for an MT cell. The upper, dot-dash line indicates the response of the cell to the preferred direction alone, and the points indicate the response of the cell when each of eight directions was superimposed upon this preferred motion (the point for motion $180^{\circ}$ from preferred is plotted twice). It can be seen that all motions other than the preferred itself reduced the response of the cell as compared to the preferred direction alone, indicating that the data so far presented are probably not unique to opposite directions of motion. For this cell, the largest effects were actually found for motions of orthogonal direction. $B$, As a comparison, the direction tuning of the same cell as in $A$ is presented. The direction tuning was produced by simply drifting a single-surface pattern in each of eight dircctions (again, the $180^{\circ}$ point is repeated). The slight differences in peak response are probably due to the fact that these two curves were gathered at separate times (not in a pseudointerleaved paradigm, as other results). It is clear that motions at $45^{\circ}$ and $90^{\circ}$ to the preferred direction produce an excitatory response. These are exactly the same motions that produce an inhibitory effect in $A$.

the response to the preferred direction to be reduced! It is therefore clear that the same stimulus can cause an increase or decrease in the cell's firing rate, depending upon the context in which it is presented.

All of the 11 neurons on which we performed this test gave roughly similar results, though the width of the suppression tuning varied from cell to cell. In order to show this variation, we normalized the response of each cell with respect to the firing rate in the preferred direction and calculated the mean and $\mathrm{SE}$ of the tuning; these results are shown in Figure 11. The sup- 


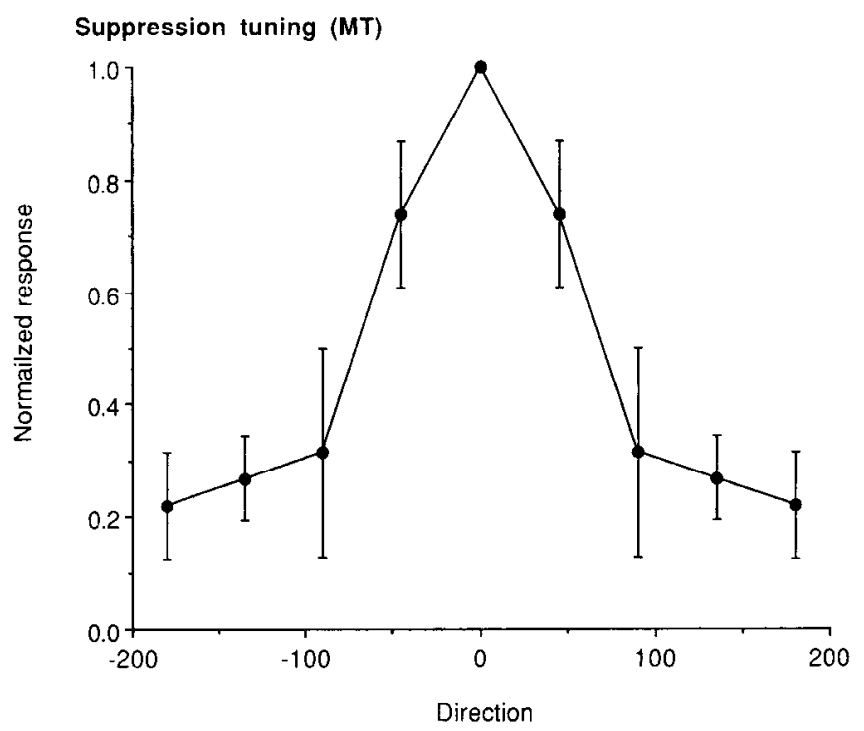

Figure 11. The direction tuning of the suppressive effect across a population of MT neurons $(N=11)$. The test for each neuron was that described in Figure $10 \mathrm{~A}$. The response in each condition was then scaled to the response to the preferred direction, and the mean and SE are portrayed in this figure.

pressive effect develops quickly as direction of the suppressor is moved away from the preferred up to around $90^{\circ}$, and then increases very slowly as direction of the suppressor is increased to $180^{\circ}$. As can be seen from the SEs, there was considerable variation from cell to cell in the shape of the suppression tuning curve.

\section{The nature of the inhibition}

\section{Preferred/antipreferred titration}

Inhibitory influences can modify the response of a cell in two ways (Blomfield, 1974). The first process can be thought of as a linear mechanism by which IPSPs and EPSPs simply add to produce the final total. This process produces a subtraction. The second process is a nonlinear mechanism that produces a ratio of the excitatory and inhibitory input. This process produces a division. However, these can be regarded as the limiting cases, and in reality, strong hyperpolarizations or thresholds can serve to introduce nonlinearities that can mimic a pure divisionlike process (for discussion, see Amthor and Grzywacz, 1991).

In order to investigate whether the inhibitory effects described above are more like a subtraction or a division, we "titrated" the effects of the preferred and antipreferred directions of movement by systematically varying the dot density in each of these directions. Two representative neurons from area MT are portrayed in Figure 12, $A$ and $B$. The open circles represent the neuron's response to changes in the dot density of the preferred direction presented alone. As dot density is increased, the response of the neuron rises sharply, then begins to saturate and asymptotes at fairly low dot densities. When in addition a number of dots were drifted in the antipreferred direction, the shape of this function is altered. In each case, the rise in response with dot density is less steep, and the greater the density of dots in the antipreferred direction, the more gradual the rise in the function. As the function saturates rapidly for the preferred direction alone, there is a range of dot densities that cause no increase in response to the preferred direction alone, but cause
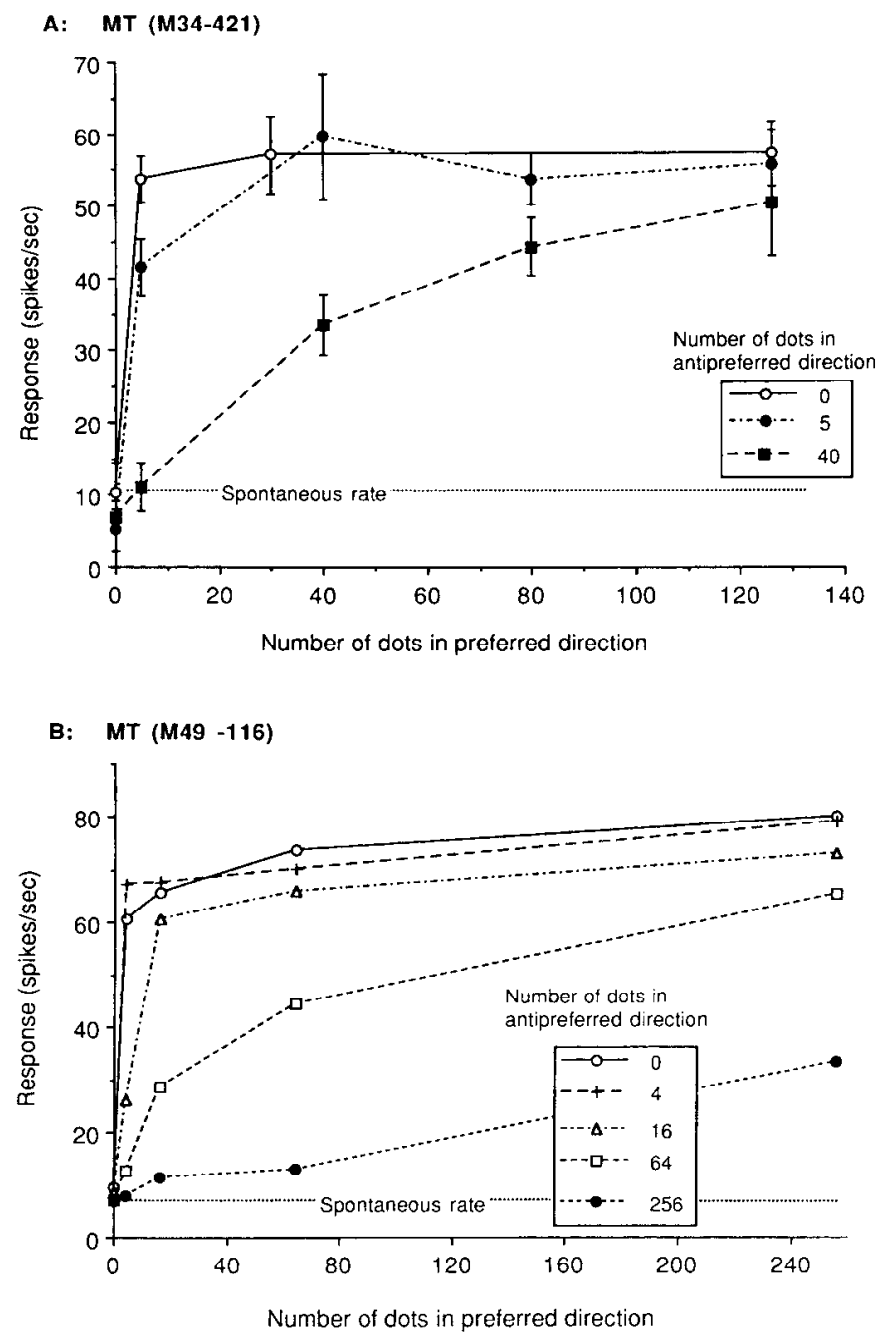

Figure 12. The response of two MT cells $(A$ and $B)$ is plotted as a function of the number of dots in the preferred direction. Each curve corresponds to repeating this function, with a certain number of dots (given in legends) always drifting in the antipreferred direction. All trials for each cell were presented in a pseudorandom order. The $S D$ of each point is plotted in $A$ but omitted in $B$ in order to avoid cluttering. When no dots are drifted in the antipreferred direction, the curves rise sharply and asymptote with increasing dot density of the preferred direction. The addition of dots in the antipreferred direction causes this rise to be more gradual but does not necessarily reduce the maximum response of the cell (though this is now reached at a greater dot density). Increasing the dot density in the antipreferred direction increases these effects.

an increase in response when there are also some dots moving in the antipreferred direction.

An ideal subtractive inhibition would cause the function to be shifted by a constant amount down the vertical axis, and the size of this shift would be a monotonic function of the density in the antipreferred direction (Fig. 13A). Hence, the slope of this function should not be affected, which is clearly not the case (however, a subtractive inhibition followed by a nonlinearity could produce a change in slope; Amthor and Grzywacz, 1991). A divisionlike inhibition does indeed predict that the slope of the function should become more gradual as dot density in the antipreferred direction increases, and therefore the results point to a divisionlike operation being at the root of the inhibitory effect. A simple divisionlike operation would predict that all functions would saturate at the same dot density and, because 


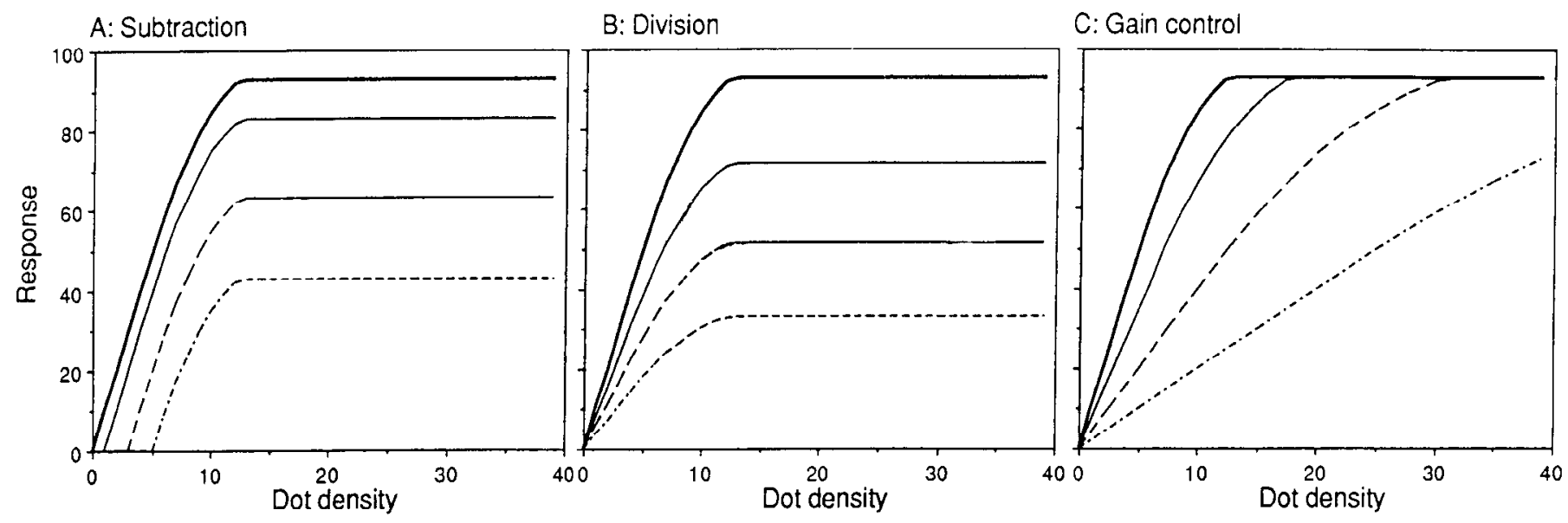

Figure 13. A simulation of the expected effects of various forms of inhibition upon the response versus dot number curves for cells. $A$, The curve shown with the thick line simulates the function produced by the preferred direction alone. It rises quickly with increasing dot density, then begins to saturate, and finally asymptotes. This approximates the action of real MT neurons (see Fig. 12) and is similar in form to data obtained from cat and monkey V1 neurons for response versus contrast (Albrecht and Hamilton, 1982). This curve is also reproduced in $B$ and $C$. The other curves represent the actions of a purely subtractive inhibition, with curves farther down the vertical axis representing greater inhibition. $B$, As in $A$, except that the curves now represent the action of a division-type operation occurring after the mechanism of saturation. $C$, As in $A$, except that the curves represent the action of a division-type operation occurring before the mechanism of saturation. Such a process can be considered as gain control.

of the more gradual rise, at a different response rate (see Fig. $13 B$ ). We found, however, that the functions continued to rise after the dot density at which the preferred function alone saturated. These functions continued to rise with increasing dot density and saturated only when they reached the same response rate at which the function for the preferred direction alone saturated (which is at a much higher dot density). This implies that the mechanism of saturation occurs after the divisionlike operation to produce functions similar to those portrayed in Figure 12. Such an operation can be conceptualized as a gain control upon the incoming excitatory information, which we reproduce by scaling of the effects of dot density in Figure $13 \mathrm{C}$. These functions were produced by dividing the horizontal axis by a constant (it can be conceptualized as stretching the function along the horizontal axis). In all MT neurons from which we were able to obtain sufficient results to distinguish between the various functions described above, all corresponded to those portrayed in Figure $13 C$.

\section{Direction tuning}

A prediction of the divisionlike inhibition hypothesis is that the inhibition (when plotted on linear coordinates) increases with increasing response strength of the neuron. For an inhibition factor of 2, if a neuron would respond without inhibition at 10 spikes/sec, then with inhibition it would respond at 5 spikes/ sec; whereas a rate of 100 spikes/sec would be cut to 50 spikes/ sec. One simple way to vary the response of MT neurons is to shift the direction of motion of a test stimulus. If the inhibition is divisionlike, we would expect to see the greatest net loss in the number of spikes per second when the movement is in the preferred direction, and a decreasing loss as the direction is moved away from the preferred direction.

To test this prediction, we measured directional tuning curves with and without 64 dots moving in the antipreferred direction in an interleaved block of trials. Representative results are shown in Figure 14. As can be seen in this figure, the function with dots in the antipreferred direction is predicted by a simple division factor on the function obtained for the single surface. We also obtained results from the relatively rare V1 cells that showed suppression by using a higher dot density in the antipreferred direction; these, too, showed similar effects.

\section{Discussion}

Relationship to previous work

Most physiological investigations of visual function have concentrated on the response of neurons to discrete small stimuli within their classical receptive fields. However, more recently, these studies have been extended so that the test stimuli are placed in the context of a more complicated environment, which may extend well beyond the classical receptive field (for review, see Allman et al., 1985b). Allman et al. (1985a) have shown that for many MT cells of the owl monkey the response to a bar or a dot pattern moving within the cell's receptive field can be suppressed by the addition of a surround moving in the same direction, and some cells can be facilitated by the surround moving in a different direction. The present experiment differs from that of Allman et al. (1985a) in that our two patterns are coextensive and the effects can be produced entirely within the classical receptive field. Hence, our result that the response to the preferred movement is suppressed by movements in a different direction (the opposite result to Allman et al., 1985a) does not contradict, but complements the results of Allman et al. [1985a; see also Tanaka et al. (1986) for similar results in area MT of macaques, and Hammond and MacKay (1981) and Hammond and Smith (1983) for similar results in cat striate cortex].

Hoffman and Distler (1989) recently reported testing neurons in the nucleus of the optic tract in the pretectum and the dorsal terminal nucleus of the accessory optic tract with stimuli made by superimposing two oppositely moving random dot patterns. The two neurons they examined fired less to the twopattern stimulus than to either of the individual patterns alone, a result comparable to our results in area MT. 


\section{Transparency}

The percept of the casual observer of our combination stimulus is of two transparent surfaces drifting through one another (Clarke, 1977; van Doorn et al., 1985). The formation of the percept of two surfaces must be achieved purely on the basis of the motion information available in the display, as all other cues such as color and form have been deliberately removed.

\section{Computational models}

Much recent effort has been applied in attempting to produce algorithms that calculate the "optic flow field" (Fennema and Thompson, 1979; Horn and Schunk, 1981; Hildreth, 1984; Heeger, 1987; Uras et al., 1988; Yuille and Grzywacz, 1988; Bülthoff el al., 1989; Wang et al., 1989). These algorithms follow the general principle of calculating a local velocity component at each point in the image (as in the primary motion-detection stage), and then smoothing or averaging the resultant field (as in the motion-integration stage) on the premise that the velocity in most parts of the image will be varying in a gradual manner (some algorithms perform these operations in discrete stages, while others do this simultaneously). 'I hese algorithms account well for some known properties of human motion detection, for cxamplc, motion capture (MacKay, 1961) and cooperativity (Chang and Julesz, 1985; Williams et al., 1986), but have difficulty when velocity changes sharply, such as at the juncture between objects (though some models have suggested solutions to this problem; Hutchinson et al., 1988; Grzywacz and Yuille, 1990). These models cannot handle transparent motion stimuli because a smoothing or averaging operation demands a single answer at each point in the image. Indeed, with our opposed motion stimuli, the smoothing operation would result in no computed motion whatsoever.

These models are not the only ones that fail under conditions of motion transparency. For instance, the models of Reichardt (1961) and Adelson and Bergen (1985) both involve a stage at which motions of opposite direction are subtracted from one another (for details, see Adelson and Bergen) thus eliminating any response to our transparent stimuli. Some models (e.g., Watson and Ahumada, 1985) employ an OR gate between opposite directions; again, this excludes motion transparency.

These computational algorithms work in two stages: (1) measuring the local velocity components and (2) spatially integrating these measurements. It is therefore tempting to consider the hypothesis that the two areas we recorded from (V1 and MT) are the physiological counterparts of these stages. The relative lack of suppression in V1 suggests that these cells act like directional filters, extracting their preferred movement from the two-surface stimulus. Thus, within V1, there would be a group of neurons signaling one direction of motion, and another signaling the other direction of motion. As the interactions between these groups are weak, they could be active at the same time and represent the two directions of motion present in the stimulus. This segmentation of the two directions of motion into two populations allows more than one local motion vector to be represented at each point in space, something current computational models do not allow at their output stage. Second, this segmentation might allow smoothing or averaging operations to be applied separately to each of the populations, hence providing a mechanism for representing optic flow fields that are not inherently unique at each point in the image. Such a technique has been recently shown to enhance an algorithm for

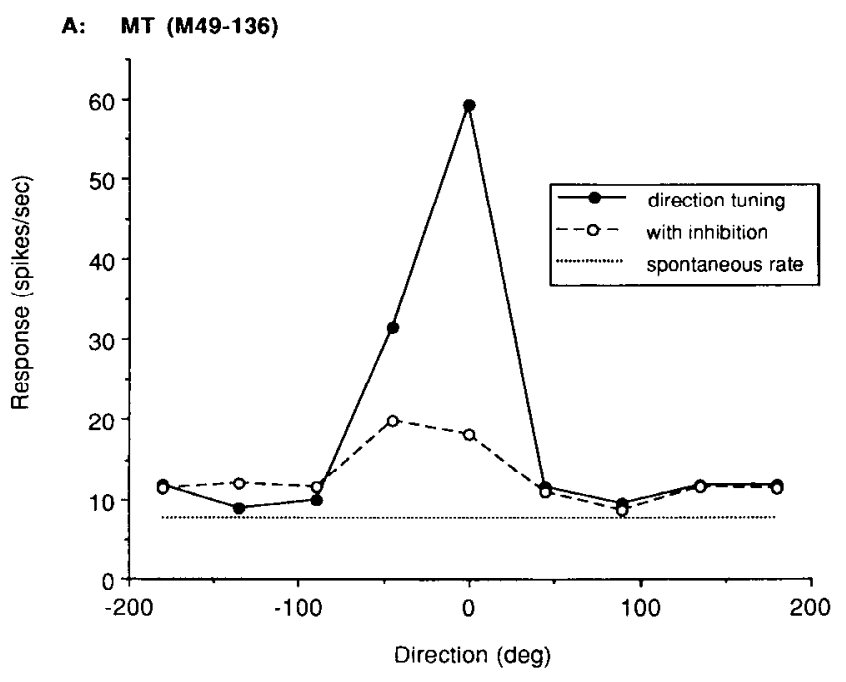

B: $\quad$ MT (M49-134)

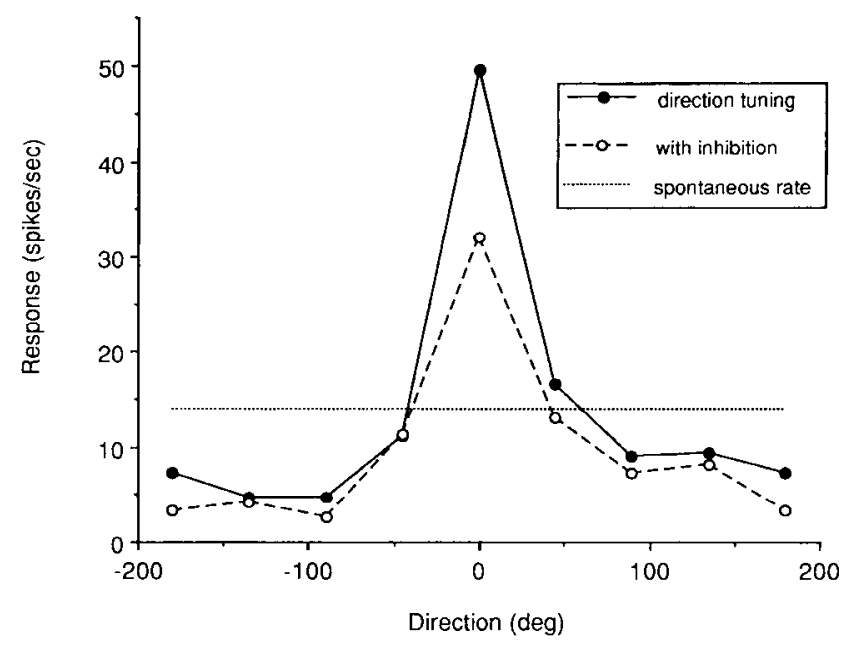

Figure 14. The direction tuning of two MT cells under conditions of just a single surface (solid circles) and when an equal number of dots were always drifting in the antipreferred direction $\left(180^{\circ}\right.$, open circles). The spontaneous rate is also shown as the straight line. The greatest suppression occurs at $0^{\circ}$, when the cell would be most active.

computing structure-from-motion for a transparent rotating cylinder (Ando et al., 1990).

The cells within area MT, on the other hand, produced a far greater response to their preferred direction alone than when it was presented as part of a transparent motion stimulus. Hence, these neurons do not act as simple directional filters. The strong interactions seen in this area may be indicative of a spatial integration of the local velocity signals arising in V1, and as such, MT is a strong candidate area for the spatial integration operations of the computational theories (Wang et al., 1989). It should be noted that MT could represent the subtraction stage proposed by Adelson and Bergen (1985), if the subtraction is approximated by a division.

\section{Psychophysics}

From the above results, we can make some clear predictions concerning the perception of transparent motions. If motion thresholds are governed by the actions of cells in Vl, we should 
expect that single motion surfaces would be almost as detectable as when this motion is embedded in a transparent motion stimulus. However, much evidence points to MT being an area important for the perception of motion. Lesioning this arca results in considerable elevations of thresholds for detecting motion in random dot patterns (Siegel and Andersen, 1986; Newsome and Paré, 1988); the action of single neurons seems well correlated with the perceptual thresholds of the monkey (Newsome et al., 1989); and many psychophysical motion thresholds are in accord with the known properties of this area (Baker and Braddick, 1985; Golomb et al., 1985; Mikami et al., 1986b; Newsome et al., 1986; Snowden and Braddick, 1990). This predicts that a motion surface will be more detectable when presented on its own than when this motion surface is embedded in a transparent motion stimulus, because of the inhibition prevalent within MT. Recent psychophysical evidence supports this idea by showing that movements in orthogonal directions reduce the upper displacement limit for apparent motion (Snowden, 1989, 1990). The upper displacement thresholds may be processed in MT, which has larger receptive fields compared to V1 and is consistent with greater inhibition in MT. Further, motions of opposite directions (as in the stimuli we used) can increase the observer's contrast threshold for detecting movement (Mather and Moulden, 1983) and reduce the ability to see correlated movements (Lappin and Kottas, 1981) when compared to a single surface (see also Sutherland, 1961; Moulden and Mather, 1978; Watson et al., 1980; Stroymeyer et al., 1984). All these authors interpret their results in terms of inhibitory interactions between different directions of motion, which we now suggest arise within area MT. In this context, we should point out that, even though MT neurons respond less to transparent motion than to motion in their preferred direction alone, each of the two moving surfaces still activates a separate subpopulation of neurons (though the neurons' firing rates are on average reduced by $40 \%)$.

Further psychophysical work has involved changes in the perceived direction of motion of a stimulus when two directions are superimposed (Marshak and Sekuler, 1979; Mather and Moulden, 1980), or when a single direction is viewed after prolonged inspection of a pattern moving in a somewhat different direction (Levinson and Sekuler, 1976; Mather, 1980). These authors also interpret their results in terms of inhibitory interactions between different directions of motion (Mather and Moulden, 1980).

Several studies of structure-from-motion perception using random dot stimuli indicate that the visual system can interpolate three-dimensional surfaces from sparse motion data (Siegel and Andersen, 1988, 1990; Husain et al., 1989; Treue et al., 1991). In these experiments, the stimuli were transparent hollow rotating cylinders. A recent computational model of three-dimensional structure-from-motion perception that uses surface interpolation and accounts for the results of these studies requires that the two surfaces present in the stimulus be segregated first and then smoothed (interpolated) individually for the structure-from-motion computation (Ando et al., 1990). Our data indicate that V1 would be able to perform such a surface segregation based on the opposite direction of motion of the front and back surface. MT, while dampened in its response by the transparent stimulus, might still be sufficiently activated to perform the smoothing and interpolation needed for the extraction of surfaces for perceiving structure from motion.

Figure 7 demonstrates that the addition of stationary and dynamic noise to the preferred direction of motion reduces the response of the cell, but that this reduction is not as great as that caused by the opposite direction of motion. This is in accord with psychophysical findings that show that stationary and dynamic noise reduces subjects' ability to report direction of movement, but does not compromise this ability as much as coherent movement (Snowden, 1989). Such stimuli also activate many cells in areas V1 and MT. If, as suggested above, these cells that are activated then send inhibitory signals to cells that have different direction selectivity, then the overall effect upon a cell that is responding to its preferred direction of movement will be a reduction of its response (Snowden, 1989). These results are therefore easily accounted for under the current theoretical framework. Also of great interest are recent reports of patients who have received damage to a brain area thought to be a human analog of area MT. The addition of small amounts of stationary or dynamic noise to an otherwise coherently moving pattern completely masked the motion for these patients (Vaina et al., 1991; Baker et al., 1990). Similar effects have been observed in strobc-rcarcd cats (Pastcrnak ct al., 1990). This suggests that the inhibitory interactions that we demonstrate in area MT may play an important role in reducing noise.

\section{The aperture problem}

If a straight moving contour is viewed through a small aperture, its direction of movement can only be estimated to within $180^{\circ}$ (Wohlgemuth, 1911)-the so-called aperture problem. A possible solution to this problem is to have each oriented contour provide a "line of constraint" for the possible motion, and thus two or more such contours will provide a solution to the aperture problem through their "intersection of constraints" (Adelson and Movshon, 1982). Individual neurons could, in theory, respond either to the motion of each orientated contour (component motion) or to the overall movement of the pattern (pattern motion). Movshon et al. (1985) have examined this issue using plaid pattcrns (the supcrimposition of two sine-wave gratings). They found that all V1 cells respond in a component fashion, whereas a substantial number of MT neurons respond in a pattern fashion (see also Rodman and Albright, 1989). Movshon et al. (1985) interpret this result as suggesting a twostage motion process: extraction of the motion perpendicular to the oriented contours, followed by a nonlinear computation of the intersection of constraints (psychophysical evidence is also provided to support this claim). How this nonlinear computation might be achieved is not suggested. Bülthoff et al. (1989) have, however, demonstrated that a computational model, involving a two-stage process not dissimilar to that suggested by the present data, simulates human performance when presented with the aperture problem. Their model is similar to the one suggested here in that it involves a local motion measurement followed by summation and competition between different directions of motion. Indeed, they tentatively identify the first step with area V1 neurons and the summation and competition stages with area MT. The only major difference between their model and the present model is that the competition stage in their model is "winner-take-all," whereas we suggest a divisionlike inhibition that does not necessarily produce a "winnertake-all" answer (see also Yuille and Grzywacz, 1989).

All area MT cells we recorded from showed a suppressive effect (see Figs. 4, 5) and thus do not fall readily into two classes that could correspond to the component and pattern types of responses. However, from the data provided by Movshon et al. 
(1985), there appears to be a continuum rather than two discrete classes. The issue of the relationship between "pattern versus component" and "degree of suppression" therefore requires a more exhaustive and detailed study before a statement can be made. It should be noted, though, that the basis for the distinction between pattern and component cells is the ambiguity inherent in plaids made from gratings, because the aperture problem prevents the determination of the direction of motion of a grating. This is not the case for random dot patterns, and thus two random dot patterns moving in different directions never cohere.

\section{Motion segmentation}

Psychophysical studies have demonstrated that objects can be segmented on the basis of motion information alone (Braddick, 1974). The large receptive fields of area MT suggest that boundaries defined by motion alone might appear blurry and poorly defined. However, perceptually these borders are very crisp. In the same vein, area MT neurons were shown to be suppressed by motion borders, as they were by the transparent stimulus. Thus, it would appear that the detection of motion borders is signaled by cells in another visual area. It is possible, however, that a lack of activity would be interpreted as a border, because the population image in area MT would be of cells signaling two directions of movement away from the border and much reduced activity would be present on the border. A similar suggestion was made by Grzywacz and Yuille (1990) on theoretical grounds. It is also possible that the nonclassical surround of MT cells described by Allman et al. (1985a), which often facilitate responses from the classical receptive field when movement is in the opposite direction to the surround, could make MT sensitive to motion borders.

\section{Models of direction selectivity}

There are many models of how a neuron might achieve a difference in its response when the same pattern is moved in different directions. One of the most influential models was put forward by Barlow and Levick (1965) after experiments on retinal ganglion cells of the rabbit. They found that flashing a single test bar within the receptive field elicited a response from the neuron, but the response to this test bar disappeared if another conditioning bar was presented immediately before and to one side of the test bar (thus mimicking the antipreferred direction of motion). If the conditioning bar was presented on the other side of the test bar (thus mimicking the preferred direction of motion), the response to the test bar did not disappear. They concluded that the directional response of the bar was achieved due to the first bar causing an inhibitory signal to be passed in one direction (the antipreferred), thus vetoing any response in this direction, while leaving the response to the other (preferred) direction unaffected. Such a model predicts that the addition of the antipreferred direction onto the preferred direction (our twosurface stimulus) would cause many inhibitory signals to be generated, which would reduce the response to the preferred direction. We found very few V1 cells that were affected in this way, and this raises the possibility that the mechanism whereby primate VI neurons achieve directionality is not the inhibitory veto mechanism of the rabbit retina. ${ }^{1}$ One possibility consistent with our findings in V1 would be a facilitatory mechanism, a mechanism considered by Barlow and Levick (1965), but that was inconsistent with the rabbit retina cells. Here, the conditioning bar would not cause inhibition in the antipreferred di- rection, but would send a facilitatory signal in the preferred direction. If the Barlow and Levick model can be considered as an AND-NOT operation, the facilitatory model can be considered as an AND operation (though an analog version seems more likely). Such a mechanism would respond equally well to the preferred direction stimulus in the single- and two-surface conditions, just as many of the V1 neurons do.

The question of the mechanism of directionality has been considered many times in many species, and it is worth a brief review of the findings to put our hypothesis in context. Many models can be considered variants of the Reichardt detector (Reichardt, 1961) developed from consideration of the fly's visual system. They have three qualities: (1) two inputs separated in space, (2) an asymmetry between the inputs so that different directions of motion cause different responses, and (3) an interaction to compare these two inputs (for review, see Borst and Egelhaaf, 1989). The Reichardt detector has a multiplication as its interaction, and multiplications can be achieved by either inhibitory or excitatory mechanisms (Torre and Poggio, 1978; Koch et al., 1986; Grzywacz and Koch, 1987). In cat striate cortex, there is ample evidence for an inhibitory mechanism from experiments that are conceptually similar to that of Barlow and Levick (1965) (Goodwin and Henry, 1975; Goodwin et al., 1975; Ganz and Felder, 1984; Emerson et al., 1987; Baker and Cynader, 1988) and from pharmacological manipulation of the inputs to a neuron (see Sillito, 1979). However, other authors have reported somewhat contradictory results. Douglas et al. (1988) failed to find any large conductance changes in area 17 neurons in cat, which are predicted by the veto model (the socalled "shunting inhibition"; Poggio and Koch, 1987). Movshon et al. (1978) repeated the Barlow and Levick (1965) two-bar interaction experiments on complex neurons of cat striate cortex and found evidence for facilitatory interactions rather than inhibitory ones. Hence, it appears that both facilitatory and inhibitory mechanisms exist in this species. While we have suggested that many primate V1 neurons might use a facilitatory mechanism, it is clear that there may be some inhibitory mechanisms, too. More direct experiments are required to reveal the relative importance of the two mechanisms. A possible reason for the use of facilitatory mechanisms is that an animal with only inhibitory mechanisms would, in principle, not see transparent motions.

Barlow-Levick-type experiments have also been performed in area MT of the alert macaque (Mikami et al., 1986a). They found evidence for inhibitory interactions in every neuron, and also for facilitatory interactions in most neurons. Our results are in accord with these findings. Do, then, the inhibitory interactions we found correspond to the workings of a BarlowLevick-type veto operation? We have reason to suspect not. The inhibition sent in the antipreferred direction of Barlow and Levick's (1965) model is caused not by movement in the antipreferred direction, but simply by the presence of a pattern at all. Hence, the addition of a stationary or dynamic noise pattern should reduce the response of MT neurons as effectively as movement in the antipreferred direction. We found this not to be the case. The addition of stationary or dynamic noise did reduce the response to the preferred direction somewhat, but the reduction was considerably smaller than that elicited by the

\footnotetext{
${ }^{\prime}$ Grzywacz and Amthor (1989) have argued that even in the rabbit retina direction selectivity is formed by a nondirectional inhibition and a directional facilitation.
} 
antipreferred direction. Second, if the inhibition of the BarlowLevick model is confined to specific subunits within the receptive field [as suggested by Barlow and Levick (1965) and by Ganz and Felder (1984)], then splitting the motions into discrete sections should eliminate the suppressive effect. The suppressive effect was found to weaken under these conditions for the shear stimulus (see Figs. 8, 9) but was certainly not eliminated.

If we reject the Barlow-Levick-type inhibition as a candidate for the suppressive effects shown in area MT, what is the mechanism? One candidate mechanism is that the inhibition stems from competitive interactions between neurons with different preferred directions of motion, a notion with strong psychophysical (Levinson and Sekuler, 1976; Marshak and Sekuler, 1979; Mather and Moulden, 1980, 1983; Chang and Julesz, 1984, 1985; Williams et al., 1986; Williams and Phillips, 1987; Nawrot and Sekuler, 1989; Snowden, 1989; Snowden and Braddick, 1989) and computational foundations (Grzywacz and Yuille, 1990).

\section{Comparison with other species}

Our results point to two stages of processing of motion information in monkey cortex. An extraction of the motion energy in each direction at each point in the image (performed in V1) is followed by an interaction between directions of motion (evident in the response of MT neurons). Other species face similar demands in their environments, and it may therefore be the case that a similar strategy for motion computation will be evident in other species. Of course, the visual systems of other species vary immensely in their anatomy, so the site of these operations will be displaced relative to the monkey.

In the rabbit, directionally selective cells can be found as early as the retinal ganglion cells (Barlow et al., 1964). Levick et al. (1969) performed an experiment similar in conception to those reported here on these cells. They found that the response to a spot of light moving in the cell's preferred direction was unaffected by the addition of a second spot moving in the null direction. However, if the same test was performed on the directionally selective cells of the rabbit $\mathrm{LGN}$, a strong inhibitory effect was found. Thus, the response of the rabbit retinal ganglion cells appears to mimic monkey V1 cells, and those of rabbit LGN mimic those of monkey MT.

The $\mathrm{H} 1$ neuron of the fly is believed to gain its directionally selective responses from the pooling of small field units termed "elementary motion detectors" (for review, see Franceschini et al., 1989) - a two-stage process. The properties of each stage can be isolated by recording the response of the $\mathrm{H} 1$ neuron to widefield movement (the second, pooling stage) or to the same stimulus behind a narrow slit that eliminates pooling and thus isolates the elementary motion detectors (the first stage). Egelhaaf et al. (1990) measured the activity of both stages with and without the application of GABA agonists (GABA is a neurotransmitter thought to underlie inhibitory interactions: Bormann, 1988). They found that the response of the first stage was unaffected by GABA agonists, whereas the second, pooling stage was affected. Thus, the first stage of motion processing in the fly does not appear to use GABA inhibition, whereas the second stage does. This appears to parallel our results of a lack of inhibitory effects at the first stage of motion processing in the monkey (V1), but the presence of inhibitory effects at the second stage (MT). Further, the action of GABA is thought to produce a shunting inhibition (Grzywacz and Koch, 1987; Schmid and
Bülthoff, 1988), which would appear as a divisionlike operation (see below).

In the cat, directionally selective cells are first found in the striate cortex. Kaji and Kawabata (1985) have performed an experiment similar to ours on complex cells in cat striate cortex. While no information is given concerning the population as a whole, it is clear that some cells show a suppression of the response to their preferred direction when a stimulus of a different direction is superimposed. These cells resemble our MT cells, and the V1 cells that showed a suppressive effect. The relative strength and abundance of the suppressive effect in cat and monkey striate cortex may well be different, with the monkey showing a much smaller effect (or fewer cells) than the cat. Gulyás et al. (1987) have shown that the response to a moving bar is suppressed by texture background patterns moving in the same direction in $55 \%$ of cat striate neurons, but a similar effect is observed in only $10 \%$ of monkey striate neurons (see also Orban et al., 1987). It therefore appears that some aspects of motion processing that occur in striate cortex of cats are delayed until MT in the monkey. Hence, the response to a bar can be suppressed by background texture in area MT (Tanaka et al., 1986), especially in the layers not receiving a direct projection from V1, that is, outside layer IV (Lagae et al., 1989). Our results are consistent with the findings that many of the interactions required for this suppressive behavior are performed on cells in area MT rather than those in area V1.

From these data, it appears that there are strong parallels in the way motion is processed between very different species, though the location of each stage of processing may be very different.

\section{The nature of the inhibition}

Inhibitory influences are widespread throughout cortex (Eccles, 1969; Benevento et al., 1972) and have already been shown to play a major role in shaping the response properties of neurons tuned to the orientation of a stimulus (Blakemore and Tobin, 1972; Rose, 1977; Sillito, 1977, 1979; Tsumoto et al., 1979; Burr et al., 1981; Morrone et al., 1982; Kaji et al., 1983; Ferster, 1986; Ramoa et al., 1986; Ferster and Koch, 1987; Bonds, 1989). One major question concerns the computational operation that inhibitory synapses perform. Blomfield (1974) suggests that two basic opcrations can be performcd, depending upon the sitc of the inhibitory synapse (soma or dendrite) and their relationship to the site of excitatory innervation. One operation involves the linear addition of IPSPs and EPSPs and appears as a subtractive factor on the cells' output, whereas the second operation involves shunting away the excitation flowing toward the soma and appears as a division factor (in the limiting cases). Our results (Figs. 12,14) show that the expected response to a single direction alone is reduced by addition of the antipreferred direction in such a manner that the expected output is divided by a constant factor (for a constant antipreferred stimulus), provided the response is not saturated. Increasing the strength of movement in the antipreferred direction increases this factor (Fig. 12). These results therefore favor the notion of a divisionlike inhibition (occurring before response saturation).

\section{Divisionlike inhibition}

The notion of a divisionlike action of inhibition is not new. Various cellular models have considered the neurotransmitter GABA to play such a role in the nervous system (Dreifuss et 
al., 1969; Krnjević, 1974; Torre and Poggio, 1978; Grzywacz and Koch, 1987; Schmid and Bülthoff, 1988). Its action is thought to create low-resistance pathways through the cell membrane, which acts to short-circuit some of the current flowing toward the soma. Thus, recording intracellularly, its effects would not be seen as IPSPs; hence, it has often been referred to as silent or shunting inhibition (Torre and Poggio, 1978).

Divisionlike inhibition has been previously demonstrated in cat striate cortex by experiments comparing the response of neurons to single bars or gratings and when two such patterns that differ in orientation are superimposed. It therefore appears that these interactions are important in the analysis of contours and spatial pattern (Morrone et al., 1982, 1987; Ramoa et al., 1986). Rose (1977) has further shown that application of GABA agonists reduces orientation selectivity (see also Sillito, 1977, 1979) and that the reduction in response is proportional to the strength of the expected response (before application of GABA agonist), thus pointing to a divisionlike operation. Similar divisionlike interactions have also been suggested for interactions between oriented contours for human vision (Morrone and Burr, 1986; Burr and Morrone, 1987). Dean et al. (1980) also showed divisionlike inhibition between opposite directions of motion. They measured responses of cat area 17 neurons as a function of contrast for stimuli drifting in the preferred direction and found that the addition of a second grating moving in the antipreferred direction caused the function relating contrast to response to rise more gradually, but that the contrast threshold for a response did not change. This result is similar to our findings in area MT of the monkey.

\section{Overall view of motion processing}

Our results suggest that there is a motion strcam through the primate cortex that is organized in a hierarchical fashion. Area V1 appears to extract motion energy in each direction at each point of the image, and then MT combines these estimates through inhibitory interactions. Thus, V1 could provide the basis for segmenting the image, whereas the interactions in MT may serve to ease signal-to-noise problems (Snowden and Braddick, 1989) and to smooth across motion estimates (Treue et al., 1991).

\section{References}

Adelson EH, Bergen JR (1985) Spatiotemporal energy models for the perception of motion. J Opt Soc Am A 2:284-299.

Adelson EH, Movshon JA (1982) Phenomenal coherence of moving visual patterns. Nature 300:523-525.

Albrecht DG, Hamilton DB (1982) Striate cortex of monkey and cat: contrast response function. J Neurophysiol 48:217-237.

Albright TD (1984) Direction and orientation selectivity of neurons in visual area M' $\mathrm{I}$ of the macaque. J Neurophysiol 52:1106-1130.

Allman J, Miezin F, McGuiness E (1985a) Direction- and velocityspecific responses from beyond the classical receptive field in the middle temporal visual area (MT). Perception 14:105-126.

Allman J, Miezin F, McGuiness E (1985b) Stimulus specific responses from beyond the classical receptive field: neurophysiological mechanisms for local-global comparisons in visual neurons. Annu Rev Neurosci 8:407-430.

Amthor FR, Grzywacz NM (1991) The nonlinearity of the inhibition underlying retinal directional selectivity. Visual Neurosci 6:197-206.

Andersen RA, Mountcastle VB (1983) The influence of the angle of gaze upon the excitability of the light sensitive neurons of the postcrior parietal cortex. J Neurosci 3:532-548.

Andersen RA, Snowden RJ, Treue S, Graziano M (1990a) Hierarchical processing of motion in the visual cortex of monkey. Cold Spring Harbor Symposia on Quantitative Biology, in press.

Andersen RA, Asanuma CC, Essick G, Siegel RM (1990b) Corticocortical connections of anatomically defined subdivisions within the inferior parietal lobe. J Comp Neurol 296:65-113.

Andersen RA, Bracewell RM, Barash S, Gnadt JW, Fogassi L (1990c) Eye position effects on visual, memory, and saccade-related activity in areas LIP and 7a of macaque. J Neurosci 10:1176-1196.

Ando H, Hildreth EC, Treue S, Andersen RA (1990) Recovering 3-D structure from motion with surface reconstruction. Soc Neurosci Abstr $16: 962$.

Baker CL Jr, Braddick OJ (1985) Eccentricity-dependent scaling of the limits for short range apparent motion. Vision Res 25:803-812.

Baker CL Jr, Cynader MS (1988) Space-time separability of direction selectivity in cat striate cortex neurons. Vision Res 28:239-246.

Baker CL Jr, Hess RF, Zihl J (1990) The "motion-blind" patient: perception of random dot "limited lifetime" motion. Invest Ophthalmol Vis Sci [Suppl] 31:239.

Barlow HB, Levick WR (1965) The mechanism of directionally selective units in the rabbit's retina. J Physiol (Lond) 178:477-504.

Barlow HB, Hill RM, Levick WR (1964) Retinal ganglion cells responding selectively to direction and speed of image motion in the rabbit. J Physiol (Lond) 173:377-407.

Benevento LA, Creutzfeldt OD, Kuhnt V (1972) Significance of intracortical inhibition in the visual cortex. Nature 238:124-126.

Blakemore C, Tobin EA (1972) Lateral inhibition between orientation detectors in the cat's visual cortex. Exp Brain Res 15:439-440.

Blomfield S (1974) Arithmetic operations performed by nerve cells. Brain Res 69:115-124.

Bonds AB (1989) Role of inhibition in the specification of orientation selectivity of cells in the cat striate cortex. Visual Neurosci 2:41-55.

Bormann J (1988) Electrophysiology of $\mathrm{GABA}_{a}$ and $\mathrm{GABA}_{b}$ receptor subtypes. Trends Neurosci 11:112-116.

Borst A, Egelhaaf M (1989) Principles of visual motion detection. Trends Neurosci 12:297-306.

Braddick OJ (1974) A short-range process in apparent motion. Vision Res 14:519-527.

Britten KH, Newsome WT (1990) Responses of MT neurons to discontinuous motion. Invest Ophthalmol Vis Sci [Suppl] 31:238.

Bülthoff II, Little J, Poggio T (1989) A parallel algorithm for rcaltime computation of optical flow. Nature 337:549-553.

Burr DC, Morrone MC (1987) Inhibitory interactions in the human visual system revealed with pattern-evoked potentials. J Physiol (Lond) 389:1-21.

Burr DC, Morrone C, Maffei L (1981) Intra-cortical inhibition prevents simple cells from responding to textured visual patterns. Exp Brain Res 43:455-458.

Chang JJ, Julesz B (1984) Cooperative phenomena in apparent motion perception of random-dot cinematograms. Vision Res 24:1781-1788.

Chang JJ, Julesz B (1985) Cooperative and non-cooperative processes of apparent motion of random dot cinematograms. Spatial Vision 1: 39-45.

Clarke PGH (1977) Subjective standstill caused by interaction of moving patterns. Vision Res 17:1243.

Dean AF, Hess RF, Tolhurst DJ (1980) Divisive inhibition involved in direction selectivity. J Physiol (Lond) 308:84P.

De Valois RL, Yund EW, Kepler NK (1982) The orientation and direction selectivity of cells in macaque visual cortex. Vision Res 22: 531-544.

Douglas RJ, Martin KAC, Whitteridge D (1988) Selective responses of visual cortical cells do not depend on shunting inhibition. Nature 332:642-644.

Dow BM, Vautin RG, Bauer R (1985) The mapping of visual space onto foveal striate cortex in the macaque monkey. J Neurosci 5:890902.

Dreifuss JJ, Kelly JS, Krnjević K (1969) Cortical inhibition and $\gamma$-aminobutyric acid. Exp Brain Res 9:137-154.

Eccles JC (1969) The inhibitory pathways of the central nervous system. Liverpool: Liverpool UP.

Egelhaaf M, Borst A, Pilz B (1990) The role of GABA in detecting visual motion. Brain Res 509:156-160.

Emerson RC, Citron MC, Vaughin WJ, Klein SA (1987) Nonlinear directionally selective subunits in complex cells of cat striate cortex. J Neurophysiol 58:33-65.

Erickson RG, Snowden RJ, Andersen RA, Treue S (1989) Directional 
neurons in awake rhesus monkeys: implications for motion transparency. Soc Neurosci Abstr 15:323.

Fennema CL, Thompson WB (1979) Velocity determination in scenes containing several moving objects. Comp Graph Image Proc 9:301315.

Ferster D (1986) Orientation selectivity of synaptic potentials in neurones of cat primary visual cortex. J Neurosci 6:1284-1301.

Ferster D, Koch C (1987) Neuronal connections underlying orientation selectivity in cat visual cortex. Trends Neurosci 10:487-491.

Franceschini N, Riehle A, Nestour AL (1989) Directionally selective motion detection by insect neurons. In: Facets of vision (Stavenga DG, Hardie RC, eds), pp 360-390. Heidelberg: Springer.

Fries W, Keizer K, Kuypers HGJ (1985) Large layer V1 cells in macaque striate cortex (Meynert cells) project to both superior colliculus and prestriate visual area V5. Exp Brain Res 58:613-616.

Gallyas F (1979) Silver staining of myelin by means of physical development. Neurol Res 1:203-209.

Ganz L, Felder R (1984) Mechanism of directional selectivity in simple cells of the cat's visual cortex analyzed with stationary flash sequences. J Neurophysiol 51:294-324.

Gattass R, Gross CG (1981) Visual topography of striate projection zone (MT) in posterior temporal sulcus of the macaque. J Neurophysiol 46:621-638.

Golomb B, Andersen RA, Nakayama K, MacLeod DIA, Wong A (1985) Visual thresholds for shearing motion in monkey and man. Vision Res 25:813-820.

Goodwin AW, Henry GH (1975) Direction selectivity of complex cells in a comparison with simple cells. J Neurophysiol 38:1524-1540.

Goodwin AW, Henry GH, Bishop PO (1975) Direction selectivity of simple striate cells: properties and mechanism. J Neurophysiol 38: 1500-1523.

Grimson WEL (1981) From images to surfaces. A computational study of the human early visual system. Cambridge, MA: MIT Press.

Grzywacz NM, Amthor FR (1989) Facilitation in on-off directionally selective ganglion cells of the rabbit retina. Soc Neurosci Abstr 15: 969.

Grzywacz NM, Koch C (1987) Functional properties of models for direction selectivity in the retina. Synapse 1:417-434.

Grzywacz NM, Yuille AL (1990) A model for the estimate of local image velocity by cells in the visual cortex. Proc R Soc Lond [Biol] 239:129-161.

Gulyás B, Orban GA, Spileers W (1987) A moving noise background modulates responses of striate neurons to moving bars in the cat but not the monkey. J Physiol (Lond) 390:28P.

Hammond P, MacKay DM (1981) Modulatory influences of moving textured backgrounds on responsiveness of simple cells in feline striate cortex. J Physiol (Lond) 319:431-442.

Hammond P, Smith AT (1983) Directional tuning interactions between moving oriented and textured stimuli in complex cells of feline striate cortex. J Physiol (Lond) 342:35-49.

Hawken MJ, Parker AJ, Lund JS (1988) Laminar organization and contrast sensitivity of direction-selective cells in the striate cortex of the old world monkey. J Neurosci 8:3541-3548.

Heeger DJ (1987) Model for the extraction of image flow. J Opt Soc Am A 4:1455-1471.

Hildreth EC (1984) The computation of the velocity field. Proc R Soc Lond [Biol] 221:189-220.

Hoffmann K-, Distler C (1989) Quantitative analysis of visual receptive fields of neurons in nucleus of the optic tract and dorsal terminal nucleus of the accessory tract in macaque monkey. J Neurophysiol 62:416-428.

Horn BKP, Schunk BG (1981) Determining optical flow. Artif Intell 17:185-203.

Hubel D, Wiesel T (1968) Receptive fields and functional architecture of the monkey striate cortex. J Physiol (Lond) 195:215-243.

Husain M, Treue S, Andersen RA (1989) Surface interpolation in three-dimensional structure-from-motion perception. Neural Comput 1:324-333.

Hutchinson J, Koch C, Luo J, Mead C (1988) Computing motion using analog and binary resistive networks. IEEE Comput 21:52-61.

Judge SJ, Richmond BJ, Shu FC (1980) Implantation of magnetic search coils for measurement of eye position: an improved method. Vision Res 20:535-537.

Kaji S, Kawabata N (1985) Neural interactions of two moving patterns in the direction and orientation domain in the complex cells of cat's visual cortex. Vision Res 25:749-753.
Kaji S, Tamane S, Kawabata N (1983) Neural interactions of two slits in the orientation domain in the visual units of the cat. Vision Res 23:883-886.

Koch C, Poggio T, Torre V (1986) Computations in the vertebrate retina: gain enhancement, differentiation and motion discrimination. Trends Neurosci 9:204-211.

Kowler E, van der Steen J, Tamminga EP, Collewijn H (1984) Voluntary selection of the target for smooth eye movement in the presence of superimposed, full-field stationary and moving stimuli. Vision Res 24:1789-1798.

Krnjević K (1974) Chemical nature of synaptic transmission in vertebrates. Physiol Rev 54:418-540.

Lagae L, Gulyás B, Raiguel S, Orban GA (1989) Laminar analysis of motion information processing in macaque V5. Brain Res 496:361367

Lappin JS, Kottas BL (1981) The perceptual coherence of moving visual patterns. Acta Psychol 48:163-174.

Levick WR, Oyster CW, Takahashi E (1969) Rabbit lateral geniculate nucleus: sharpener of directional information. Science 165:712-714.

Levinson E, Sekuler R (1976) Adaptation alters perceived direction of motion. Vision Res 16:779-781.

MacKay DM (1961) Visual effects of non-redundant stimulation. Nature 192:739-740.

Marshak WM, Sekuler R (1979) Mutual repulsion between moving visual targets. Science 205:1399-1401.

Mather $G$ (1980) The movement aftereffect and a distribution-shift model for coding the direction of visual movement. Perception 9: 379-382.

Mather G, Moulden B (1980) A simultaneous shift in apparent directions: further evidence for a 'distribution-shift' model of direction coding. Q J Exp Psychol 32:325-333.

Mather G, Moulden B (1983) Thresholds for movement direction: two directions are less detectable than one. Q J Exp Psychol 35:513518.

Maunsell JHR, Van Essen DC (1983) The connections of the middle temporal visual area (MT) and their relationship to a cortical hierarchy in the macaque monkey. $J$ Neurosci 3:2563-2586.

Mikami A, Newsome WT, Wurtz RH (1986a) Motion selectivity in macaque visual cortex. I. Mechanisms of direction and speed selectivity in extrastriate area MT. J Neurophysiol 55:1308-1327.

Mikami A, Newsome WT, Wurtz RH (1986b) Motion selectivity in macaque visual cortex: II. Spatio-temporal range of directional interactions in MT and V1. J Neurophysiol 55:1328-1339.

Morgan MJ, Ward R (1980) Interocular delay produces depth in subjectively moving noise patterns. Q J Exp Psychol 32:387-395.

Morrone MC, Burr DC. (1986) Evidence for the existence and development of visual inhibition in humans. Nature 321:235-237.

Morrone MC, Burr DC, Maffei L (1982) Functional implications of cross-orientation inhibition of cortical cells. I. Neurophysiological evidence. Proc R Soc Lond [Biol] 216:335-354.

Morrone MC, Burr DC, Speed HD (1987) Cross-orientation inhibition in cat is GABA mediated. Exp Brain Res 67:635-644.

Moulden B, Mather $G$ (1978) In defence of a ratio model for movement detection at threshold. Q J Exp Psychol 30:505-520.

Movshon JA, Thompson ID, Tolhurst DJ (1978) Receptive field organization of complex cells in the cat's striate cortex. J Physiol (Lond) 283:79-99.

Movshon JA, Adelson EH, Gizzi MS, Newsome WT (1985) The analysis of moving visual patterns. In: Pattern recognition mechanisms (Chagas C, Gattass R, Gross C, eds), Rome: Vatican Press. (Pont Acad Sci Scr Varia 54:117-151.)

Nawrot M, Sekuler R (1989) Assimilation and contrast in motion perception: explorations in cooperativity. Invest Ophthalmol Vis Sci [Suppl] 30:72.

Newsome WT, Paré EB (1988) A selective impairment of motion perception following lesions of the middle temporal visual area (MT). J Neurosci 8:2201-2211.

Newsome WT, Mikami A, Wurtz RH (1986) Motion selectivity in macaque visual vortex. III. Psychophysics and physiology of apparent motion. J Neurophysiol 55:1340-1351.

Newsome WT, Britten KH, Movshon JA (1989) Neuronal correlates of a perceptual decision. Nature 341:52-54.

Orban GA, Gulyás B, Spileers W (1987) A moving noise background modulates responses to moving bars of monkey $V 2$ cells but not of monkey V1 cells. Invest Ophthalmol Vis Sci [Suppl] 28:197.

Pasternak T, Albano JE, Harvitt DM (1990) The role of directionally 
selective neurons in the perception of global motion. J Neurosci 10: 3079-3086.

Poggio T, Koch C (1987) Synapses that compute motion. Sci Am 256: $46-52$.

Ramoa AS, Shadlen M, Skottun BC, Freeman RD (1986) A comparison of inhibition in orientation and spatial frequency selectivity of cat visual cortex. Nature 321:237-239.

Reichardt W (1961) Autocorrelation: a principle of the evaluation of sensory information by the central nervous system. In: Sensory communication (Rosenblith WA, ed). New York: Wiley.

Robinson DA (1963) A method of measuring eye movement using a sceral search coil in a magnetic field. IEEE Trans Biomed Eng 10: 137-145.

Rodman HR, Albright TD (1989) Single-unit analysis of pattern-motion selective properties in the middle temporal visual area (MT). Exp Brain Res 75:53-64.

Rose D (1977) On the arithmetic operation performed by inhibitory synapses onto the neuronal soma. Exp Brain Res 28:221-223.

Saito H-A, Yukie M, Tanaka K, Hikosaka K, Fukada Y, Iwai E (1986) Integration of direction signals of image motion in the superior temporal sulcus of the macaque monkey. J Neurosci 6:145-157.

Schmid A, Bülthoff H (1988) Using neuropharmacology to distinguish between excitatory and inhibitory movement detection mechanisms in the fly Calliphora erythrocephala. Biol Cybern 59:71-80.

Shipp S, Zeki S (1985) Segregated output to area V5 from layer 4B of macaque monkey striate cortex. J Physiol (Lond) 369:32P.

Siegel RM, Andersen RA (1986) Motion perceptual deficits following ibotenic acid lesions of the middle temporal area in the behaving rhesus monkey. Soc Neurosci Abstr 12:1183.

Siegel RM, Andersen RA (1988) Perception of three-dimensional structure from motion in monkey and man. Nature 331:259-261.

Siegel RM, Andersen RA (1990) Perception of structure-from-motion in monkey and man. J Cogn Neurosci 2:306-319.

Sillito AM (1977) Inhibitory processes underlying the directional specificity of simple, complex and hypercomplex cells in the cat's visual cortex. J Physiol (Lond) 271:699-720.

Sillito AM (1979) Pharmacological approach to the visual cortex. Trends Neurosci 2:196-198.

Snowden RJ (1989) Motions in orthogonal directions are mutually suppressive. J Opt Soc Am 7:1096-1101.

Snowden RJ (1990) Suppressive interactions between moving patterns: role of velocity. Percept Psychophys 47:74-78.

Snowden RJ, Braddick OJ (1989) The combination of motion signals over time. Vision Res 29:1621-1630.

Snowden RJ, Braddick OJ (1990) Differences in the processing of short-range apparent motion at small and large displacements. Vision Res 30:1211-1222.

Snowden RJ, Erickson RG, Treue S, Andersen RA (1990) Transparent stimuli reveal divisive inhibition in area $\mathrm{MT}$ of macaque. Invest Ophthalmol Vis Sci [Suppl] 31:399.

Stromeyer CF III, Kronauer RE, Madsen JC, Klein SA (1984) Opponent-movement mechanisms in human vision. J Opt Soc Am A $1: 876-884$.

Sutherland NS (1961) Figural after-effects and apparent size. Q J Exp Psychol 13:222-228.

Tanaka K, Hikosaka K, Saito H, Yukie M, Fukada Y, Iwai E (1986) Analysis of local and wide-field movements in the superior temporal visual areas of the macaque monkey. J Neurosci 6:134-144.

Torre V, Poggio T (1978) A synaptic mechanism possibly underlying directional selectivity to motion. Proc R Soc Lond [Biol] 202:409416.

Treue S, Husain M, Andersen R (1991) Human perception of structure from motion. Vision Res 31:59-75.

Tsumoto T, Eckart W, Creutzfeldt OD (1979) Modification of orientation sensitivity of cat visual cortex neurons by removal of GABAmediated inhibition. Exp Brain Res 34:351-363.

Uras S, Girosi F, Verri A, Torre V (1988) A computational approach to motion perception. Biol Cybern 60:79-87.

Vaina LM, LeMay M, Bienfang DC, Choi AY, Nakyama K (1991) Intact "biological motion" and "structure from motion" perception in a patient with impaired motion mechanisms: a case study. Visual Neurosci, in press.

van Doorn AJ, Koenderink JJ, van der Grind WA (1985) Perception of movement and correlation in stoboscopically presented noise patterns. Perception 14:209-224.

Wang HT, Mathur B, Koch C (1989) Computing optical flow in the primate visual system. Neural Comput 1:92-103.

Watson AB, Ahumada AJ Jr (1985) Model of human visual-motion sensing. J Opt Soc Am A 1:322-342.

Watson AB, Thompson PG, Murphy BJ, Nachmias J (1980) Summation and discrimination of gratings moving in opposite directions. Vision Res 20:341-347.

Williams D, Phillips G, Sekuler R (1986) Hysteresis in the perception of motion direction as evidence for neural cooperativity. Nature 324 : 253-255.

Williams P, Phillips $P$ (1987) Cooperative phenomena in the perception of motion direction. J Opt Soc Am 4:878-885.

Wohlgemuth A (1911) On the aftereffect of seen motion. Br J Psychol $1: 1-117$

Yuille AL, Grzywacz NM (1988) A computational theory for the perception of coherent visual motion. Nature 333:71-74.

Yuille AL, Grzywacz NM (1989) A winner-take-all mechanism based on presynaptic inhibition feedback. Neural Comput 1:334-347.

Zcki SM (1974) Functional organization of a visual area in the posterior bank of the superior temporal sulcus of the rhesus monkey. J Physiol (Lond) 236:549-573. 